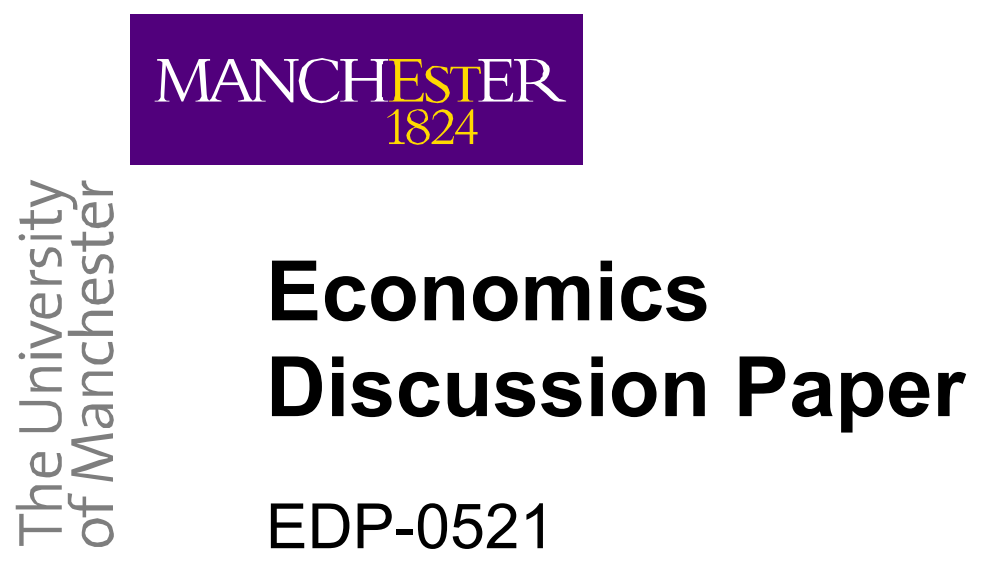

Footloose Entrepreneurs, Taxes and Subsidies

by

Pasquale Commendatore, Martin Currie and Ingrid Kubin

December 2005

martin.currie@manchester.ac.uk

School of Social Sciences,

The University of Manchester

Oxford Road

Manchester M13 9PL

United Kingdom 


\title{
Footloose Entrepreneurs, Taxes and Subsidies
}

\author{
By Pasquale Commendatore ${ }^{1}$, Martin Currie ${ }^{2}$ and Ingrid Kubin ${ }^{3}$
}

\begin{abstract}
The long-term behaviour of a discrete-time Footloose Entrepreneur model, where entrepreneurs move between regions in response to economic incentives, can involve periodic cycles, chaotic orbits, or agglomeration. The dynamical system possesses multiple attractors and displays sensitive dependence both on initial conditions and on parameters. Where governments impose tax or subsidy rates on profits, very small changes in a rate can have dramatic, and possibly unpredictable, repercussions on the spatial location of manufacturing industry and on social welfare. The complexity of the dynamics is likely to be exacerbated by competition between governments employing subsidies to attract or retain entrepreneurs.
\end{abstract}

Keywords: new economic geography, footloose entrepreneurs, taxation, dynamics.

JEL classification: F20; R1; R12.

The authors would like to acknowledge financial assistance from the Special Research Program on International Tax Coordination at Vienna University of Economics and BA.

Corresponding author:

Dr. Martin Currie martin.currie@man.ac.uk

1. Università di Napoli 'Federico II'.

2. The University of Manchester.

3. Vienna University of Economics and BA. 


\section{Footloose Entrepreneurs, Taxes and Subsidies}

The long-term behaviour of a discrete-time Footloose Entrepreneur model, where entrepreneurs move between regions in response to economic incentives, can involve periodic cycles, chaotic orbits, or agglomeration. The dynamical system possesses multiple attractors and displays sensitive dependence both on initial conditions and on parameters. Where governments impose tax or subsidy rates on profits, very small changes in a rate can have dramatic, and possibly unpredictable, repercussions on the spatial location of manufacturing industry and on social welfare. The complexity of the dynamics is likely to be exacerbated by competition between governments employing subsidies to attract or retain entrepreneurs.

\section{Introduction}

The cornerstone of the new economic geography is the Core-Periphery model, introduced by Krugman (1991) and explored in depth by Fujita, Krugman and Venables (1999). Despite its analytical intractability, the model has provided invaluable insights into the relationships between, on the one hand, the location of economic activity and, on the other, production conditions, tastes and transport costs. Important to the continuing growth of the new paradigm are: (i) the development of more tractable variants of the model; (ii) a systematic examination of the implications of new economic geography models for public policy; and (iii) confirmation of the robustness of propositions based on those models. As regards (i) and (ii), a valuable contribution is made by Economic Geography and Public 
Policy by Baldwin, Forslid, Martin, Ottaviano and Robert-Nicoud (2003), henceforth referred to as BFMOR. The authors provide comprehensive treatments not only of the seminal core-periphery model but also of a number of more tractable variants. Moreover, their wide-ranging study of the policy implications of the new economic geography embraces trade policy, taxation policy and regional policy. BFMOR devote particular attention to the Footloose Entrepreneur model, developed by Forslid (1999), Ottaviano (2001) and Forslid and Ottaviano (2003). This model - in which entrepreneurs move between regions in response to economic incentives - retains the interesting properties of the parent Core-Periphery model but is much more tractable analytically. Drawing in part on Baldwin and Krugman (2004), BFMOR use the Footloose Entrepreneur model to analyze the taxation of profits. One of their central theses is that propositions based on the basic 'smooth' neoclassical tax competition model may be invalid in the 'lumpy' new economic geography models.

The primary objective of this paper is to explore the robustness of the propositions derived from the continuous-time Footloose Entrepreneur $(F E)$ model by reformulating the model in discrete time. Since the discrete-time model can exhibit long-term behaviour involving periodic cycles, chaotic orbits or agglomeration, it is much richer in terms of its potential for explaining and understanding economic phenomena relating to industrial relocation between regions and countries. However, the discrete-time model also cautions against relying on simple comparative static propositions, whether derived from smooth neoclassical models or from the continuous-time $F E$ model.

Except for the different temporal framework, our basic Footloose Entrepreneur $(F E)$ model corresponds to that analyzed by Forslid and Ottaviano (2003) and by BFMOR in Chapter 4. As regards government intervention, we assume that governments, interested in 
the welfare of their workers, may impose taxes on entrepreneurial profits and redistribute the tax revenue to workers, or they may subsidize entrepreneurs and finance this by taxes on workers. In their analysis of taxation in Chapters 15 and 16, BFMOR also assume that governments seek to maximize the utility of their workers. However, BFMOR assume that tax revenues are spent on a public good. Specifically, they assume that "political economy considerations lead the government to adopt labourers' utility as its objective and to spending tax revenue on a public good that favours labourers over capital owners" (p. 408). The possibility of a government subsidizing profits does not arise in their model. ${ }^{1}$

As explained in Section 2, our model involves two regions with the same number of regionally immobile workers, the same tastes, the same technology and the same transport costs. Section 3 identifies the short-run general equilibrium contingent on a given spatial allocation of entrepreneurs. Section 4 completes the model by specifying the dependence of entrepreneurial migration on regional post-tax real incomes. Given the remarkable complexity of the dynamics, we examine in Section 5 the simplest case of regional symmetry where the regional tax or subsidy rates are given and the same. Our treatment here is relatively brief, since Currie and Kubin (2006) explore in detail the dynamical behaviour of a discrete-time regionally symmetric Core-Periphery model. In Section 6, we focus on the implications of differential taxation or subsidization of profits. Having highlighted the complications that result from different tax or subsidy rates, we examine the choice of rate by one government given the rate in the other region and we consider the possible implications of active competition between governments.

\footnotetext{
${ }^{1}$ In Chapter 18, BFMOR consider regional subsidies but for a very different model involving two regions in the same country and footloose physical capital, where capital owners themselves are regionally immobile.
} 


\section{Assumptions}

Both regions have a monopolistically competitive manufacturing sector and a perfectly competitive agricultural sector. Labour is used in both sectors. Each worker provides one unit of (unskilled) labour services per period. Workers are immobile between regions but instantaneously mobile between sectors within a region. Each region has $L / 2$ workers. Entrepreneurship - or 'human capital' - is used solely in manufacturing. Comprising a distinct socio-economic class, entrepreneurs are mobile between the regions at the transitions between time periods.

Consumers in both regions have Cobb-Douglas preferences over the homogeneous agricultural good and a quantity index that is a CES function of the varieties of manufactured goods. The exponents of the agricultural good and of the manufacturing composite in the common utility function - and hence the invariant shares of income devoted to the agricultural good and to manufactures - are $(1-\mu)$ and $\mu$, respectively. The constant elasticity of substitution between the manufactured varieties is denoted by $\sigma>1$; the lower $\sigma$, the greater the consumers' taste for variety.

With labour being the sole agricultural input, 1 unit of labour yields 1 unit of the agricultural product. Since neither region has enough workers to satisfy the total demand of both regions for the agricultural product, both regions always engage in agricultural production - the so-called 'non-full-specialization condition'.

Manufacturing involves increasing returns: each firm requires a fixed input of 1 entrepreneur to operate and $\beta$ units of unskilled labour services for each unit produced. The manufacturing sectors involve Dixit-Stiglitz monopolistic competition. Since 1 entrepreneur is required for each manufacturing firm, the total number of firms always 
equals the total number of entrepreneurs. Since, given the consumers' preference for variety and the increasing returns, a firm would always produce a variety different from the varieties produced by other firms, the number of varieties is always the same as the number of firms. Denoting the share of entrepreneurs located in region 1 in period $t$ by $\lambda_{t}$, the numbers of regional varieties produced in period $t$ are $n_{1, t}=\lambda_{t} N$ and $n_{2, t}=\left(1-\lambda_{t}\right) N$, where $N$ is the total number of entrepreneurs and where $0 \leq \lambda_{t} \leq 1$. The tax rate on profits in region $r$ is denoted by $\tau_{r}$, where $\tau_{r}<1$ and $r=1,2$. Any tax revenue is redistributed to the region's workers. A subsidy to entrepreneurs would involve $\tau_{r}<0$. Such a subsidy would be financed by a tax on the region's workers.

Transportation of the agricultural product between regions is costless. In contrast, transport costs for manufactures take an iceberg form: if 1 unit is shipped between the regions, $1 / T$ arrives where $T \geq 1$. 'Trade freeness' is defined as $\phi \equiv T^{1-\sigma}$ where $0<\phi \leq 1$, with $\phi=1$ representing no trade cost and with trade cost becoming prohibitive as $\phi \rightarrow 0$.

\section{Short-run General Equilibrium}

In this Section, we characterize the short-run general equilibrium in period $t$, as uniquely determined by the given spatial allocation of entrepreneurs, $\lambda_{t}$. With the instantaneous establishment of equilibrium in the agricultural market and no transport costs, the agricultural price is the same in both regions. Total expenditure on the agricultural product is $(1-\mu) Y_{1+2}$, where $Y_{1+2}$ is total ('world') income (which, as confirmed below, is invariant over time). Assuming $(1-\mu) Y_{1+2}>L / 2$, both regions produce the agricultural product. Since competition results in zero agricultural profits, the short-run equilibrium nominal wage in period $t$ is equal to the agricultural product price and therefore is always the same 
in both regions. Taking the agricultural commodity as the numeraire, its price and the wage equal 1.

Since manufacturers in both regions face the same wage in every period, all set the same mill price, $p$, using the familiar Dixit-Stiglitz pricing rule. The local price of every variety is

$$
p=\frac{\beta \sigma}{\sigma-1}
$$

The effective price paid by consumers for a variety produced in the other region is $p T$. The regional manufacturing price indices facing consumers are given by

$$
\begin{aligned}
& G_{1, t}=\left[n_{1, t} p^{1-\sigma}+n_{2, t} p^{1-\sigma} T^{1-\sigma}\right]^{\frac{1}{1-\sigma}}=\Delta_{1, t}^{\frac{1}{1-\sigma}} N^{\frac{1}{1-\sigma}} p \\
& G_{2, t}=\left[n_{1, t} p^{1-\sigma} T^{1-\sigma}+n_{2, t} p^{1-\sigma}\right]^{\frac{1}{1-\sigma}}=\Delta_{2, t}^{\frac{1}{1-\sigma}} N^{\frac{1}{1-\sigma}} p
\end{aligned}
$$

where, to simplify notation, $\Delta_{1, t} \equiv \lambda_{t}+\phi\left(1-\lambda_{t}\right)$ and $\Delta_{2, t} \equiv \phi \lambda_{t}+1-\lambda_{t}$, and where $G_{1, t}$ is decreasing in $\lambda_{t}$. Since workers and entrepreneurs have the same tastes, income redistribution per se has no direct impact on product demands. Total expenditure on manufactures is simply $\mu Y_{1+2}$. The regional demands per variety are

$$
\begin{aligned}
& d_{1, t}=\left[\mu Y_{1, t} G_{1, t}^{\sigma-1}+\mu Y_{2, t} G_{2, t}^{\sigma-1} \phi\right] p^{-\sigma}=\left[s_{t} G_{1, t}^{\sigma-1}+\left(1-s_{t}\right) G_{2, t}^{\sigma-1} \phi\right] \mu Y_{1+2} p^{-\sigma} \\
& d_{2, t}=\left[\mu Y_{1, t} G_{1, t}^{\sigma-1} \phi+\mu Y_{2, t} G_{2, t}^{\sigma-1}\right] p^{-\sigma}=\left[s_{t} G_{1, t}^{\sigma-1} \phi+\left(1-s_{t}\right) G_{2, t}^{\sigma-1}\right] \mu Y_{1+2} p^{-\sigma}
\end{aligned}
$$

where $Y_{r, t}$ is income and expenditure in region $r$ in period $t$ and where $s_{t} \equiv Y_{1, t} / Y_{1+2}$ denotes region 1's share in expenditure. 
Short-run general equilibrium in period $t$ requires that each firm meets the demand for its variety. ${ }^{2}$ For a variety produced in region $r$,

$$
q_{r, t}=d_{r, t}
$$

where $q_{r, t}$ is the output of each firm located in region $r$. From (1), the short-run equilibrium pre-tax profit per variety / entrepreneur in region $r$ is

$$
\pi_{r, t}=p q_{r, t}-\beta q_{r, t}=\frac{p q_{r, t}}{\sigma}=\frac{\beta}{\sigma-1} q_{r, t}
$$

Since profit equals the value of sales times $1 / \sigma$ and since total expenditure on manufactures is $\mu Y_{1+2}$, the total pre-tax profit received by entrepreneurs is $\mu Y_{1+2} / \sigma$. Total income is then $Y_{1+2}=L+(\mu / \sigma) Y_{1+2}$, so that

$$
Y_{1+2}=\frac{\sigma L}{\sigma-\mu} \text {. }
$$

Total pre-tax profit is therefore $\mu L /(\sigma-\mu)$. Equation (6) confirms that total income is invariant over time. From (6), $(1-\mu) Y_{1+2}>L / 2$ is equivalent to $\mu+\sigma-2 \mu \sigma>0$. The latter is the (sufficient) non-full-specialization condition expressed in terms of the utility parameters.

Using (1) to (6), the regional short-run equilibrium pre-tax profits are determined by the spatial distribution of entrepreneurs and the regional expenditure shares:

\footnotetext{
${ }^{2}$ As a result of Walras' Law, simultaneous equilibrium in all product markets implies equilibrium in the regional labour markets.
} 


$$
\begin{aligned}
& \pi_{1, t}=\frac{\mu}{\sigma} \frac{Y_{1+2}}{N}\left[\frac{s_{t}}{\lambda_{t}+\phi\left(1-\lambda_{t}\right)}+\frac{\phi\left(1-s_{t}\right)}{\phi \lambda_{t}+1-\lambda_{t}}\right]=\Psi\left[\frac{s_{t}}{\Delta_{1, t}}+\frac{\phi\left(1-s_{t}\right)}{\Delta_{2, t}}\right] \\
& \pi_{2, t}=\frac{\mu}{\sigma} \frac{Y_{1+2}}{N}\left[\frac{\phi s_{t}}{\lambda_{t}+\phi\left(1-\lambda_{t}\right)}+\frac{\left(1-s_{t}\right)}{\phi \lambda_{t}+1-\lambda_{t}}\right]=\Psi\left[\frac{\phi s_{t}}{\Delta_{1, t}}+\frac{\left(1-s_{t}\right)}{\Delta_{2, t}}\right]
\end{aligned}
$$

where $\Psi$ is the average profit per variety:

$$
\Psi \equiv \frac{\mu L}{(\sigma-\mu) N}
$$

For $\tau_{1}>0$ and $\tau_{2}>0$, the tax revenues, $\tau_{1} \lambda_{t} N \pi_{1, t}$ and $\tau_{2}\left(1-\lambda_{t}\right) N \pi_{2, t}$, are redistributed to workers. If $\tau_{r}<0$ is negative, redistribution is from workers to entrepreneurs in the region(s) concerned. Regional incomes / expenditures - unaffected by redistribution - are

$$
Y_{1, t}=\frac{L}{2}+\lambda_{t} N \pi_{1, t} \quad Y_{2, t}=\frac{L}{2}+\left(1-\lambda_{t}\right) N \pi_{2, t} .
$$

Using (6) to (9), region 1's share in total expenditure is

$$
s_{t}=\frac{Y_{1, t}}{Y_{1+2}}=\frac{\sigma-\mu}{2 \sigma}+\lambda_{t} \frac{\mu}{\sigma}\left[\frac{s_{t}}{\Delta_{1, t}}+\frac{\phi\left(1-s_{t}\right)}{\Delta_{2, t}}\right] .
$$

Rearranging gives $s_{t}$ in terms of $\lambda_{t}$ :

$$
s_{t}=\frac{(1 / 2)(\sigma-\mu)+\left(\mu \phi \lambda_{t} / \Delta_{2, t}\right)}{\sigma-\left(\mu \lambda_{t} / \Delta_{1, t}\right)+\left(\mu \phi \lambda_{t} / \Delta_{2, t}\right)}
$$

where $s_{t}$ is increasing in $\lambda_{t}$. Substituting (11) in (7), each region's short-run equilibrium pre-tax profit is determined by the spatial location of entrepreneurs, $\lambda_{t}$. The possibility of deriving closed-form solutions for the short-run equilibrium values differentiates the $F E$ model from the parent Core-Periphery model. As BFMOR (p. 91) note, this is due to the 
fact that in the $F E$ model the mobile factor is used only in meeting fixed costs in manufacturing.

Given that the agricultural price is 1, the pre-tax real income of an entrepreneur in region $r$ is

$$
\omega_{r, t}=\pi_{r, t} G_{r, t}^{-\mu}
$$

The corresponding post-tax real income is $\left(1-\tau_{r}\right) \omega_{r, t}$. For future reference, we represent the dependence of the pre-tax real income ratio on the spatial location of manufacturing by

$$
\Omega\left(\lambda_{t}\right)=\frac{\omega_{1, t}\left(\lambda_{t}\right)}{\omega_{2, t}\left(\lambda_{t}\right)}
$$

$\Omega\left(\lambda_{t}\right)$ depends solely on the utility parameters $\sigma$ and $\mu$ and on trade freeness $\phi{ }^{3}$ Since the tax rates have no incentive effect on entrepreneurial decisions within a period and no impact via product demands on short-run general equilibrium outputs and pre-tax profits, they do not affect $\Omega\left(\lambda_{t}\right)$. Since the regions have the same number of workers, the same technology and the same tastes, $\Omega\left(1-\lambda_{t}\right)=\omega_{2, t} / \omega_{1, t}$. Consequently, $\Omega\left(1-\lambda_{t}\right)=1 / \Omega\left(\lambda_{t}\right)$. Note that $\Omega(\lambda *)=1$ implies $\Omega(1-\lambda *)=1$.

Following the redistribution between workers and entrepreneurs, the per capita worker real incomes are $\left[1+2 \tau_{1} \pi_{1, t} \lambda_{t}(N / L)\right] G_{1, t}^{-\mu}$ and $\left[1+2 \tau_{2} \pi_{2, t}\left(1-\lambda_{t}\right)(N / L)\right] G_{2, t}^{-\mu}$. Their utilities are

\footnotetext{
${ }^{3} N$ and $L$ affect short-run equilibrium profits but not their ratio.
} 


$$
u_{1, t}=\xi\left[1+\frac{2 \tau_{1} \pi_{1, t} \lambda_{t} N}{L}\right] G_{1, t}^{-\mu} \quad u_{2, t}=\xi\left[1+\frac{2 \tau_{2} \pi_{2, t}\left(1-\lambda_{t}\right) N}{L}\right] G_{2, t}^{-\mu}
$$

where $\xi=\mu^{\mu}(1-\mu)^{1-\mu}$.

Particular attention focuses on core-periphery states where all manufacturing industry is concentrated in one region, i.e., $\lambda=0$ or $\lambda=1$. In the core, which could be either region,

$$
G_{C}=N^{\frac{1}{1-\sigma}} p \quad \pi_{C}=\Psi \quad \omega_{C}=\pi_{C} G_{C}^{-\mu} \quad u_{C}=\xi\left[1+\frac{2 \mu \tau_{C}}{\sigma-\mu}\right] G_{C}^{-\mu}
$$

In the periphery, where workers' incomes comprise solely wages and all manufactured goods have to be imported,

$$
G_{P}=(\phi N)^{\frac{1}{1-\sigma}} p \quad u_{P}=\xi G_{P}^{-\mu}
$$

Since no manufacturing occurs in the periphery, actual profits are zero. However, for future reference, we identify the virtual entrepreneurial returns in the periphery:

$$
\pi_{P}=\Psi\left[\phi^{-1}+\left(\phi-\phi^{-1}\right) \frac{\sigma+\mu}{2 \sigma}\right] \quad \omega_{P}=\pi_{P} G_{P}^{-\mu}
$$

where $(\sigma+\mu) / 2 \sigma$ is the core's expenditure share. $\pi_{P}$ and $\omega_{P}$ are the pre-tax returns anticipated by an entrepreneur contemplating moving from the core to the periphery. Where all manufacturing is concentrated with region 1 as the core, from (15), (16) and (17), the ratio of pre-tax real incomes is

$$
\Omega(1)=\frac{2 \phi^{1-\frac{\mu}{\sigma-1}} \sigma}{\sigma-\mu+\phi^{2}(\sigma+\mu)}
$$


Where region 1 is the periphery, $\Omega(0)=1 / \Omega(1)$.

What are the effects of a change in the spatial location of manufacturing on the functional distribution of income and on the post-transfer incomes of workers and entrepreneurs? We consider the impact of an increase in $\lambda_{t}$ on region 1.

\section{Proposition 1}

For region 1, aggregate nominal income $s_{t} Y_{1+2}$ and aggregate real income $s_{t} Y_{1+2} G_{1, t}^{-\mu}$ are increasing in $\lambda_{t}$.

This follows from the fact that an increase in $\lambda_{t}$ increases $s_{t}$ and reduces $G_{1, t}$.

\section{Proposition 2}

For region 1, aggregate nominal profit $\pi_{1, t} \lambda_{t} N$ and aggregate real profit $\pi_{1, t} \lambda_{t} N G_{1, t}^{-\mu}$ are increasing in $\lambda_{t}$.

Since an increase in $\lambda_{t}$ increases aggregate nominal income but has no effect on aggregate nominal wages, aggregate nominal profit $\pi_{1, t} \lambda_{t} N=s_{t} Y_{1+2}-(L / 2)$ increases. The fall in $G_{1, t}$ means that aggregate real profit increases.

The impact on the post-transfer incomes of workers depends on the direction of the transfer, i.e., on whether profits are being taxed or subsidized.

\section{Proposition $3 a$}

For $\tau_{1}>0$, aggregate worker nominal and real incomes in region 1 are increasing in $\lambda_{t}$ 
Since an increase in $\lambda_{t}$ increases $\pi_{1, t} \lambda_{t} N$ and thereby increases what workers receive from taxes on profits, aggregate worker nominal income $(L / 2)+\tau_{1} \pi_{1, t} \lambda_{t} N$ increases. The fall in $G_{1, t}$ means that aggregate worker real income increases. Given the fixed number of workers, nominal and real incomes per capita and, therefore, worker utility are increasing in $\lambda_{t}$

Proposition $3 b$

For $\tau_{1}=0$, an increase in $\lambda_{t}$ has no effect on aggregate worker nominal income and increases aggregate worker real income in region 1.

This follows trivially from the invariance of nominal wages and from the fall in $G_{1, t}$.

\section{Proposition $3 c$}

For $\tau_{1}<0$, whereas aggregate worker nominal income in region 1 is necessarily decreasing in $\lambda_{t}$, aggregate worker real income may be non-monotonic with respect to $\lambda_{t}$

Since an increase in $\lambda_{t}$ increases $\pi_{1, t} \lambda_{t} N$ and thereby increases what workers pay for the subsidization of profits, aggregate worker nominal income $(L / 2)+\tau_{1} \pi_{1, t} \lambda_{t} N$ must fall. The fall in $G_{1, t}$ may or may not be sufficient to counteract this, i.e., aggregate real worker income may increase or decrease. Given the fixed number of workers, the same indeterminacy applies to per capita real incomes and to worker utility. 
The impact of an increase in $\lambda_{t}$ on the welfare of entrepreneurs in region 1 is particularly complex. Given that the number of entrepreneurs located there is changing, the qualitative impacts on aggregate profit and on profit per entrepreneur may differ.

\section{Proposition 4}

The impacts of an increase in $\lambda_{t}$ on $\pi_{1, t}$ and on $\omega_{1, t}$ are ambiguous.

Depending on trade-freeness, the relationship between $\pi_{1, t}$ and $\lambda_{t}$ may be U-shaped (i.e., $\pi_{1, t}$ falls and then increases as $\lambda_{t}$ rises) or hump-shaped (i.e., $\pi_{1, t}$ increases and then falls). As regards $\omega_{1, t}=\pi_{1, t} G_{1, t}^{-\mu}$, the benefit of cost-of-living reductions to entrepreneurs qua consumers does not eliminate the indeterminacy.

The complexity carries over to the relationship between $\lambda_{t}$ and $\omega_{1, t} / \omega_{2, t}$. Figure 1 - the basis of much subsequent analysis - shows $\Omega\left(\lambda_{t}\right)$ for different values of trade freeness. For any $\phi$, an equal distribution of entrepreneurs between the regions necessarily implies the same short-run equilibrium pre-tax real income, i.e., $\Omega(1 / 2)=1$. There are two key levels of trade freeness, $\phi^{\prime}$ and $\phi^{\prime \prime}$. At $\phi=\phi^{\prime}$, the rate of change of $\Omega\left(\lambda_{t}\right)$ with respect to $\lambda_{t}$ is 0 at $\lambda=1 / 2$, as in Figure 1(b). At $\phi=\phi^{\prime \prime}$, the pre-tax real income in the core equals the virtual pre-tax real income in the periphery, i.e., $\Omega(0)=\Omega(1)=1$, as in Figure $1(\mathrm{~d})$. For 'intermediate' trade freeness, i.e., for $\phi^{\prime \prime}<\phi<\phi^{\prime}$ as in Figure 1(c), pre-tax real incomes are equal at three interior allocations, i.e., at $\lambda=1 / 2$ and at two allocations symmetric around $\lambda=1 / 2$ 


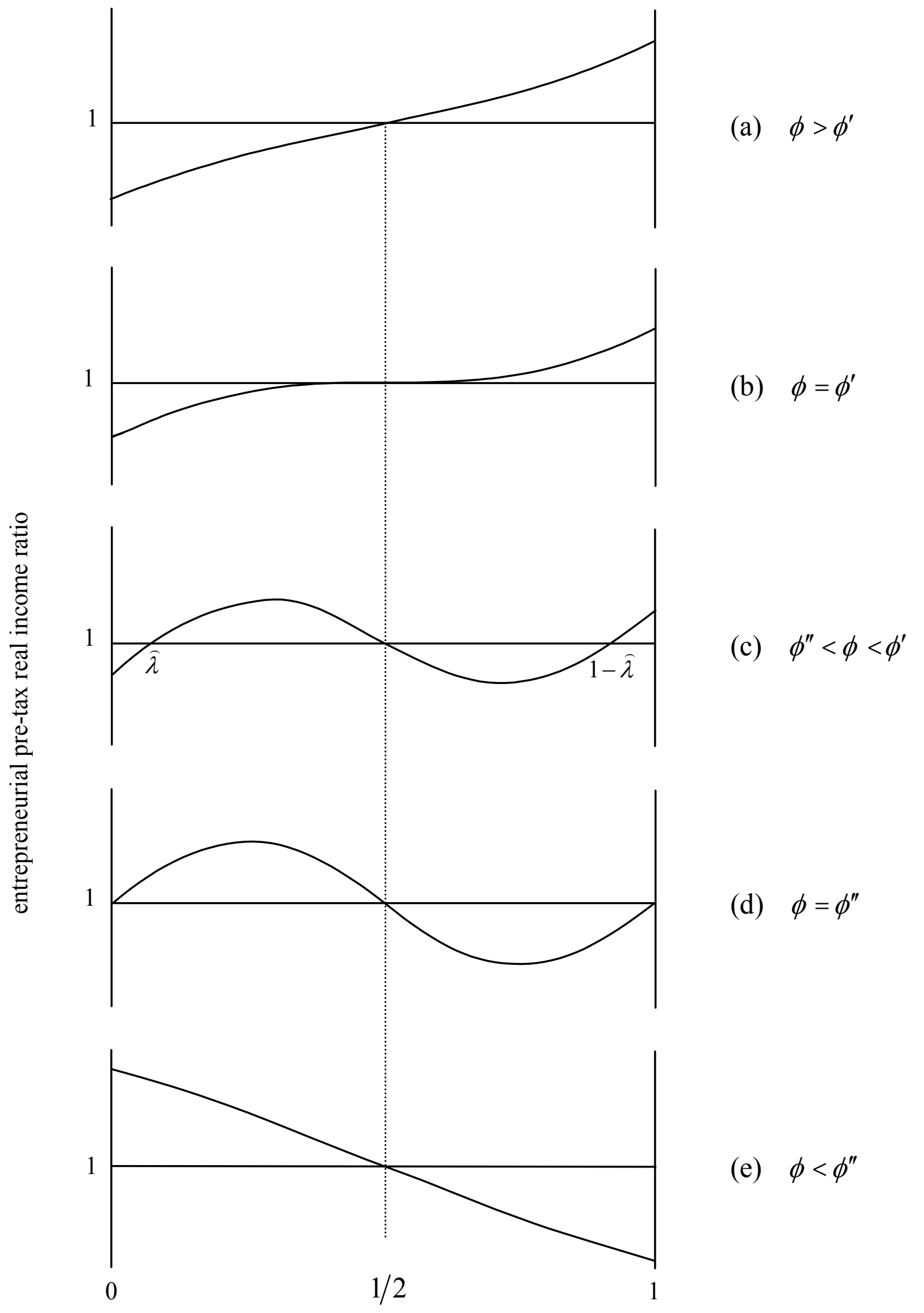

region 1's share of entrepreneurs

Figure 1 


\section{Entrepreneurial Migration and the Complete Dynamical Model}

Entrepreneurs migrate in response to economic incentives. Following Krugman (1991), BFMOR (Ch. 4) and Forslid and Ottaviano (2003), we assume myopic behaviour. Specifically, the migration of entrepreneurs at the transition between period $t$ and period $(t+1)$ depends on the ratio of post-tax real incomes in period $t$, i.e., on

$$
\frac{\left(1-\tau_{1}\right) \omega_{1, t}}{\left(1-\tau_{2}\right) \omega_{2, t}}=\Gamma \Omega\left(\lambda_{t}\right)
$$

where $\Gamma \equiv\left(1-\tau_{1}\right) /\left(1-\tau_{2}\right)$ is called the 'tax gap' by BFMOR (p. 374). Taking into account the constraint $0 \leq \lambda_{t+1} \leq 1$, the piecewise smooth one-dimensional map whereby $\lambda_{t}$ determines $\lambda_{t+1}$ is

$$
\lambda_{t+1}=Z\left(\lambda_{t}\right)=\left\{\begin{array}{ccc}
0 & \text { if } & M\left(\lambda_{t}\right)<0 \\
M\left(\lambda_{t}\right) & \text { if } & 0 \leq M\left(\lambda_{t}\right) \leq 1 \\
1 & \text { if } & M\left(\lambda_{t}\right)>1
\end{array}\right.
$$

where $\lambda_{t}$ is in $[0,1]$ implies that $\lambda_{t+1}$ is in $[0,1]$ and where

$$
M\left(\lambda_{t}\right)=\lambda_{t}+\lambda_{t}\left(1-\lambda_{t}\right) N \gamma \ln \left(\Gamma \Omega\left(\lambda_{t}\right)\right)
$$

with $\gamma>0$ denoting the migration speed. ${ }^{4}$ Given the initial condition $\lambda_{0}$, the orbit of the system is uniquely determined. The dynamical behaviour of $\lambda_{t}$ depends, via $\Omega\left(\lambda_{t}\right)$, on $\sigma$, $\mu$ and $\phi$ and, via the migration process, on $\gamma, N$ and $\Gamma$. It does not depend on $\beta$ or $L$.

\footnotetext{
${ }^{4}$ The dependence of entrepreneurial migration on the logarithm of the ratio of post-tax real incomes could be justified using a similar rationale to that used by Puga (1988) in his model of labour migration. Briefly, this
} 
An allocation $\lambda *$ is a fixed point if and only if $Z(\lambda *)=\lambda *$. There are two types of fixed point. First, since entrepreneurs do not move to a region with no manufacturing sector in the previous period, the concentration of all manufacturing in either region is necessarily a fixed point for the dynamical system. That is, from $(20), Z(0)=0$ and $Z(1)=1$. We refer to $\lambda=0$ and $\lambda=1$ as the core-periphery fixed points. The local stability of a coreperiphery fixed point depends on the stability coefficient, $Z^{\prime}(\lambda)$. At $\lambda=0$,

$$
Z^{\prime}(0)=\left\{\begin{array}{cll}
1+N \gamma \ln (\Gamma \Omega(0)) & \text { if } & M(0) \geq 0 \\
0 & \text { if } & M(0)<0
\end{array}\right.
$$

If the constraint is not binding, $Z^{\prime}(0)<1,=1$ or $>1$ as $\Omega(0)<1,=1$ or $>1$. At $\lambda=1$,

$$
Z^{\prime}(1)=\left\{\begin{array}{cll}
1-N \gamma \ln (\Gamma \Omega(1)) & \text { if } & M(1) \leq 1 \\
0 & \text { if } & M(1)>1
\end{array}\right.
$$

If the constraint is not binding, $Z^{\prime}(1)<1,=1$ or $>1$ as $\Omega(1)>1,=1$ or $<1$.

The second type of fixed point is an interior fixed point. Since migration does not occur when entrepreneurial real incomes are equal, $\Gamma \Omega\left(\lambda^{*}\right)=1$ implies that $\lambda^{*}$ is a fixed point. Depending on the parameters, there may be $0,1,2$, or 3 interior fixed points. The $F E$ model cannot be solved analytically to determine the internal fixed points. The local stability of an interior fixed point depends on

$$
Z^{\prime}(\lambda *)=M^{\prime}(\lambda *)=1+\lambda *(1-\lambda *) N \gamma \Gamma \Omega^{\prime}(\lambda *)
$$

would involve opportunities to migrate between regions arriving at a Poisson rate. Given the opportunity to migrate, an entrepreneur would face a randomly drawn migration cost. 
so that $Z^{\prime}\left(\lambda^{*}\right)<1,=1$ or $>1$ as $\Omega^{\prime}(\lambda *)<0,=0$ or $>0$.

The non-invertible map $Z\left(\lambda_{t}\right)$ displays highly complex dynamics, exhibiting cycles of every periodicity and chaotic behaviour. Let $Z^{[n]}\left(\lambda_{0}\right)$ denote the $n^{\text {th }}$ iterate. If $Z^{[k]}(\tilde{\lambda})=\tilde{\lambda}$ and if $k$ is the smallest such positive integer, $\tilde{\lambda}$ is a periodic point of period $k$ and the orbit with initial point $\tilde{\lambda}$ is a period- $k$ orbit. $^{5} \mathrm{~A}$ chaotic orbit is a bounded, nonperiodic orbit that displays sensitive dependence on the initial condition. Sensitive dependence means that orbits that begin as close together as desired eventually move apart.

\section{Regional Symmetry}

We assume initially that the governments impose the same rate, $\tau_{1}=\tau_{2}=\tau$, so that $\Gamma=1$. With a uniform rate, the implications of taxation or subsidization are confined to income distribution between workers and entrepreneurs. Since workers and entrepreneurs have the same tastes, redistribution has no impact on product demands and no effect on the short-run general equilibrium pre-tax profits. Since the ratio of entrepreneurial real incomes is the same before and after taxes, the level of $\tau$ has no effect on entrepreneurial migration and, thereby, no repercussions on the dynamical behaviour of the system.

Since the regions are identical ex ante in all relevant respects, nothing depends on the numbering of regions. It follows that the map $Z\left(\lambda_{t}\right)$ is symmetric, i.e., $Z\left(\lambda_{t}\right)=1-Z\left(1-\lambda_{t}\right)$. The symmetry of $Z\left(\lambda_{t}\right)$ implies that, given a period- $k$ orbit, either

\footnotetext{
${ }^{5}$ A fixed point of $Z\left(\lambda_{t}\right)$ is a period-1 orbit. If $\tilde{\lambda}$ is a periodic point of period $k$, it is a fixed point of $Z^{[k]}\left(\lambda_{t}\right)$. Where we refer to a 'fixed point', we always have in mind a fixed point of $Z\left(\lambda_{t}\right)$.
} 
that orbit is symmetric with respect to $\lambda=1 / 2$ or there exists a period- $k$ orbit that is symmetric to it. In the former case, the orbit's basin of attraction - that is, the set of initial conditions with orbits that approach that attractor - is symmetric with respect to $\lambda=1 / 2$; in the latter case, the basins of attraction of the two orbits are symmetric with respect to each other. $^{6}$

\subsection{Comparative Dynamics}

The primary focus of the core-periphery literature is the impact on the system's behaviour of changes in trade freeness brought about by changes in transport costs. Figure 2(a) shows the dependence of the fixed points on the value of $\phi$. Figure 2(b) is a bifurcation diagram (or orbit diagram) that shows the impact of changes in $\phi$ on the qualitative nature of the system's orbit given the initial condition, assumed here to be $\lambda_{0}=0.499$.

With perfectly free trade (i.e., $\phi=1$ ), location is irrelevant and all regional allocations of entrepreneurs are fixed points. For $\phi<1$, in addition to the core-periphery fixed points, there is necessarily a symmetric fixed point $\lambda=1 / 2$. That is, since $\Gamma=1$, from (20) and (21), $\Omega(1 / 2)=1$ implies $Z(1 / 2)=1 / 2$. In Figure $2, \phi_{B}$ and $\phi_{S}$ correspond to $\phi^{\prime}$ and $\phi^{\prime \prime}$ in Figure 1 and are called the 'break point' and 'sustain point', respectively. For $\phi>\phi_{B}$, the symmetric fixed point is unstable and the core-periphery fixed points are locally stable. The instability of the symmetric fixed point follows from $\Omega^{\prime}(1 / 2)>0$, which implies

\footnotetext{
${ }^{6}$ See Currie and Kubin (2006).

${ }^{7}$ Figure 2(a) assumes $\sigma=4$ and $\mu=0.5$. Figure 2(b) assumes, in addition, that $N=100$ and $\gamma=0.5$. The orbit is determined for 5000 periods at each $\phi$ in 1000 steps from 0.35 to 0.6 . In order to identify long-term behaviour, the first 2000 iterates are discarded; the subsequent 3000 iterates are plotted.
} 


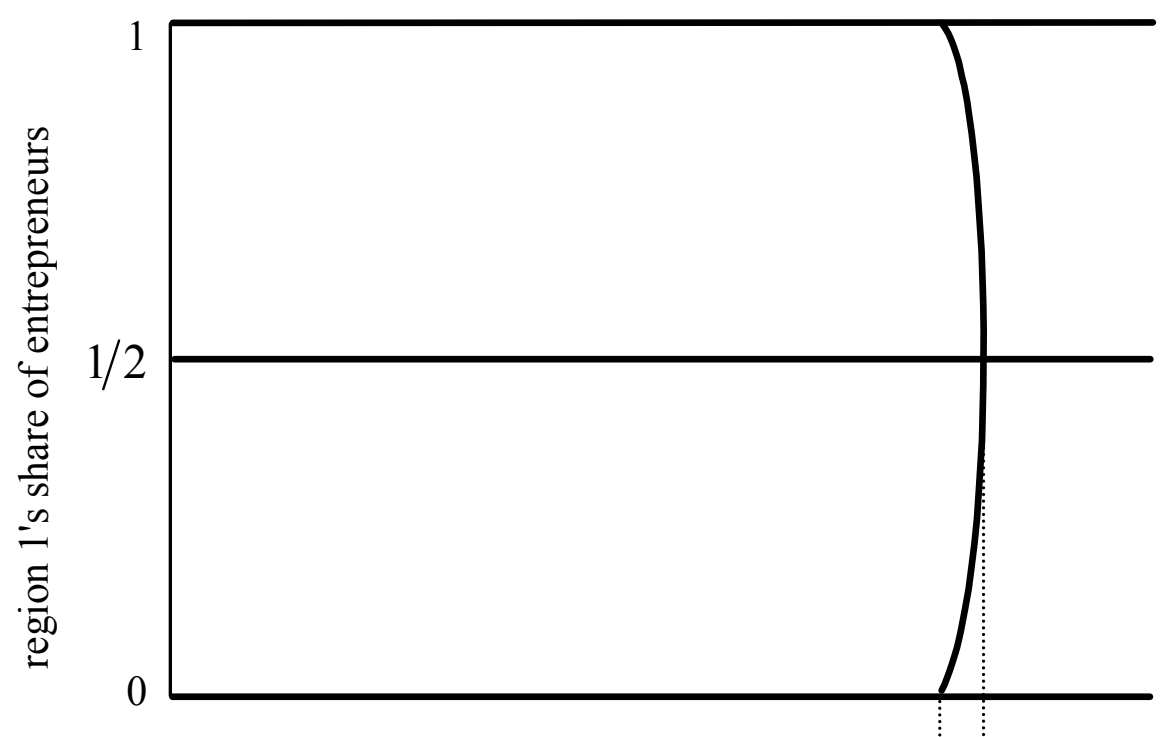

(a)

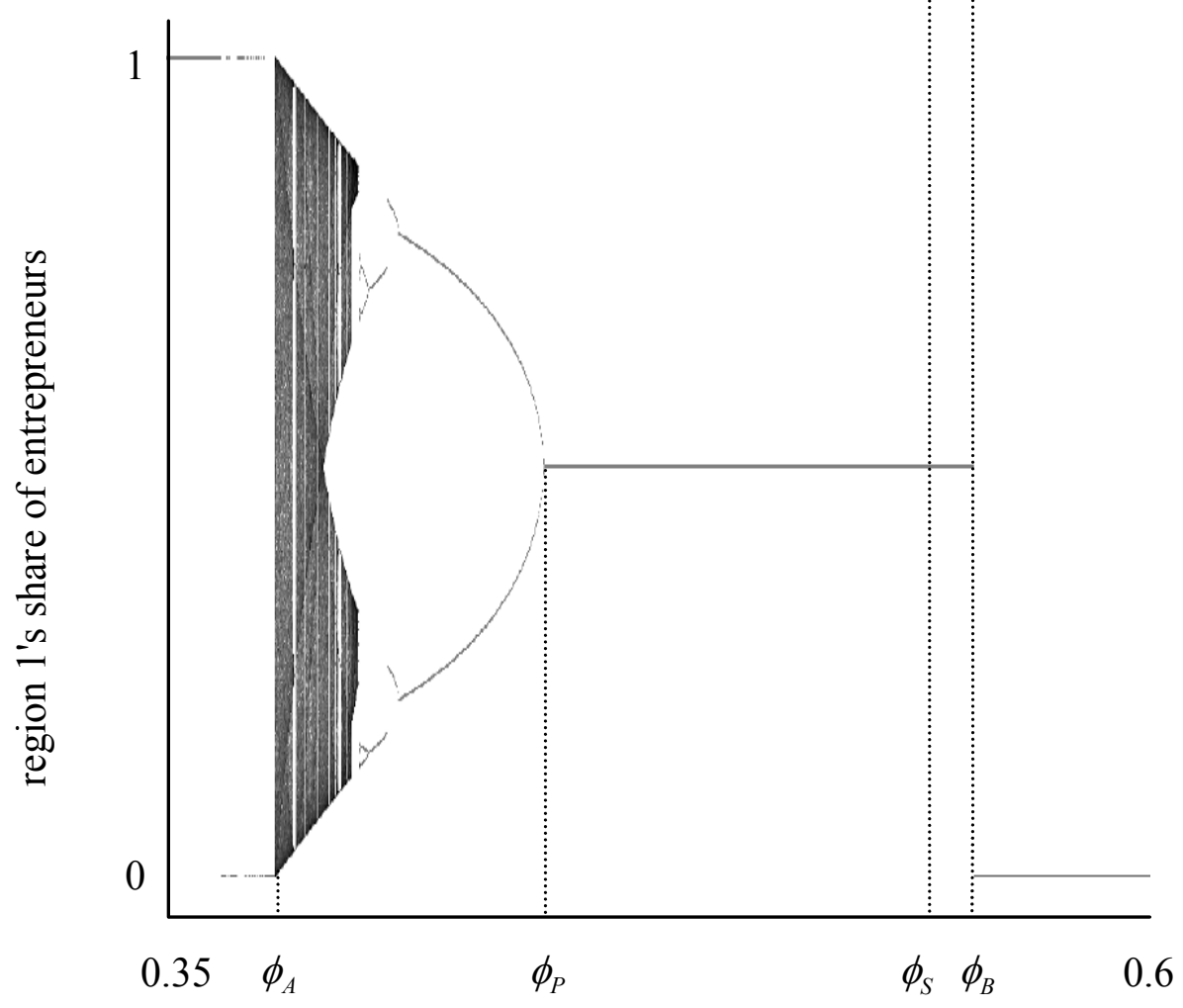

(b)

trade freeness

Figure 2 
$Z^{\prime}(1 / 2)>1$. For $\lambda_{0}<0.5$, as in Figure 2(b), agglomeration occurs in region 2 . The local stability of $\lambda=0$ follows from $\Omega(0)<1$ (i.e., the virtual real income in region 1 is less than the real income in region 2), which implies $Z^{\prime}(0)<1$. At $\phi_{B}, \Omega^{\prime}(1 / 2)=0$ which implies $Z^{\prime}(1 / 2)=1 .^{8}$ As $\phi$ falls through $\phi_{B}$, the symmetric fixed point $\lambda=1 / 2$ becomes locally stable, and a subcritical pitchfork bifurcation gives rise to two new interior asymmetric fixed points. These asymmetric fixed points, corresponding to points on the curved branches between $\phi_{B}$ and $\phi_{S}$ in Figure 2(a), are symmetric around $\lambda=1 / 2$. That is, as in Figure $1(\mathrm{c}), \Omega(\hat{\lambda})=1$ and $\Omega(1-\hat{\lambda})=1$, which imply $Z(\widehat{\lambda})=\hat{\lambda}$ and $Z(1-\hat{\lambda})=1-\hat{\lambda}$, respectively. The asymmetric fixed points are unstable since, if $\hat{\lambda}$ is such a fixed point, $\Omega^{\prime}(\hat{\lambda})>0$ implies $Z^{\prime}(\hat{\lambda})>1$. For $\phi_{S}<\phi<\phi_{B}$, the basin of attraction of $\lambda=0$ is the set of $\lambda_{0}$ in $[0, \hat{\lambda})$; that of $\lambda=1 / 2$ is the set of $\lambda_{0}$ in $(\hat{\lambda}, 1-\hat{\lambda})$; and that of $\lambda=1$ is the set of $\lambda_{0}$ in $(1-\hat{\lambda}, 1]$.

At the sustain point $\phi_{S}$, the real income of entrepreneurs in the core equals the virtual real income in the periphery, i.e., $\Omega(1)=\Omega(0)=1 .^{9}$ As $\phi$ falls through $\phi_{S}$, there is a bifurcation whereby the interior asymmetric fixed points disappear, the core-periphery fixed

\footnotetext{
${ }^{8}$ With symmetric regions, the break point depends only on the utility parameters. $\phi_{B}$ is decreasing in $\mu$ and increasing in $\sigma$. See equation 4.10 of BFMOR for the general expression for $\phi_{B}$ for symmetric regions. Provided that the utility parameters satisfy the so-called 'no-black-hole' condition $\sigma>\mu+1, \phi_{B}>0$. If that condition does not hold, agglomeration always occurs whatever the degree of trade freeness.

${ }^{9}$ With symmetric regions, the sustain point depends only on the utility parameters. $\phi_{S}$ is decreasing in $\mu$ and increasing in $\sigma$. For the general expression for $\phi_{S}$ for symmetric regions, see equation 4.11 of $B F M O R$, who confirm that the break point must exceed the sustain point.
} 
points become unstable, and the symmetric fixed point becomes an attractor for any $\lambda_{0}$ in $(0,1)$. As $\phi$ falls through $\phi_{P}$, where $Z^{\prime}(1 / 2)=-1$, the symmetric fixed point becomes unstable and a period-doubling (or flip) bifurcation gives rise to a period-2 orbit symmetric around $\lambda=1 / 2$. As $\phi$ falls further, orbits of every periodicity and chaotic behaviour occur. Graphically, the symmetry of $Z\left(\lambda_{t}\right)$ means that rotating it through $180^{\circ}$ results in the same map. The symmetry of $Z\left(\lambda_{t}\right)$ implies that, if an orbit of odd periodicity occurs, its symmetric counterpart must also exist. Figure 3 shows two attracting period-3 orbits, $A_{1}$ and $A_{2}$, that are symmetric with respect to each other. ${ }^{10}$ For $A_{1}$, region 1 cycles between $\lambda^{\prime}, \lambda^{\prime \prime}$ and $\lambda^{\prime \prime \prime}$ and region 2 cycles between $1-\lambda^{\prime}, 1-\lambda^{\prime \prime}$ and $1-\lambda^{\prime \prime \prime}$, whereas the converse applies for $A_{2}$. The basins of attraction of $A_{1}$ and $A_{2}$ are symmetric with respect to each other, i.e., if the orbit from initial point $\lambda_{0}$ is attracted to $A_{1}$, the orbit from initial point $\left(1-\lambda_{0}\right)$ must be attracted to $A_{2}{ }^{11}$ Note well that it matters greatly to a region which attractor prevails: workers in region 1 would be significantly better-off on $A_{2}$ than on $A_{1}$.

The presence of 'windows' in the bifurcation diagram confirms that dynamical behaviour can be hyper-sensitive to parameters. For example, a miniscule change in $\phi$ could lead to a change from chaotic behaviour to an orbit of low periodicity. An abrupt change in behaviour occurs as $\phi$ falls through $\phi_{A}$ in Figure 2(b). At $\phi_{A}$, given the regional symmetry, the iterate of the interior maximum of (20) is 1 and the iterate of the interior

\footnotetext{
${ }^{10}$ Figure 3 is based on $\phi=0.3869$ (and on the same parameters as Figure 2(b)).

${ }^{11}$ Each basin comprises an infinite number of intervals separated by the periodic points of the repelling period- $k$ orbits $(k \neq 3)$ and by their preimages of any rank. There are infinitely many initial points which exhibit sensitive dependence on initial conditions. A well-known implication of the existence of a period-3 orbit is that it guarantees that there are periodic orbits of all (integer) periods. On the implications of the existence of a period-3 orbit, see Alligood et al. (1996, Chapter 1).
} 


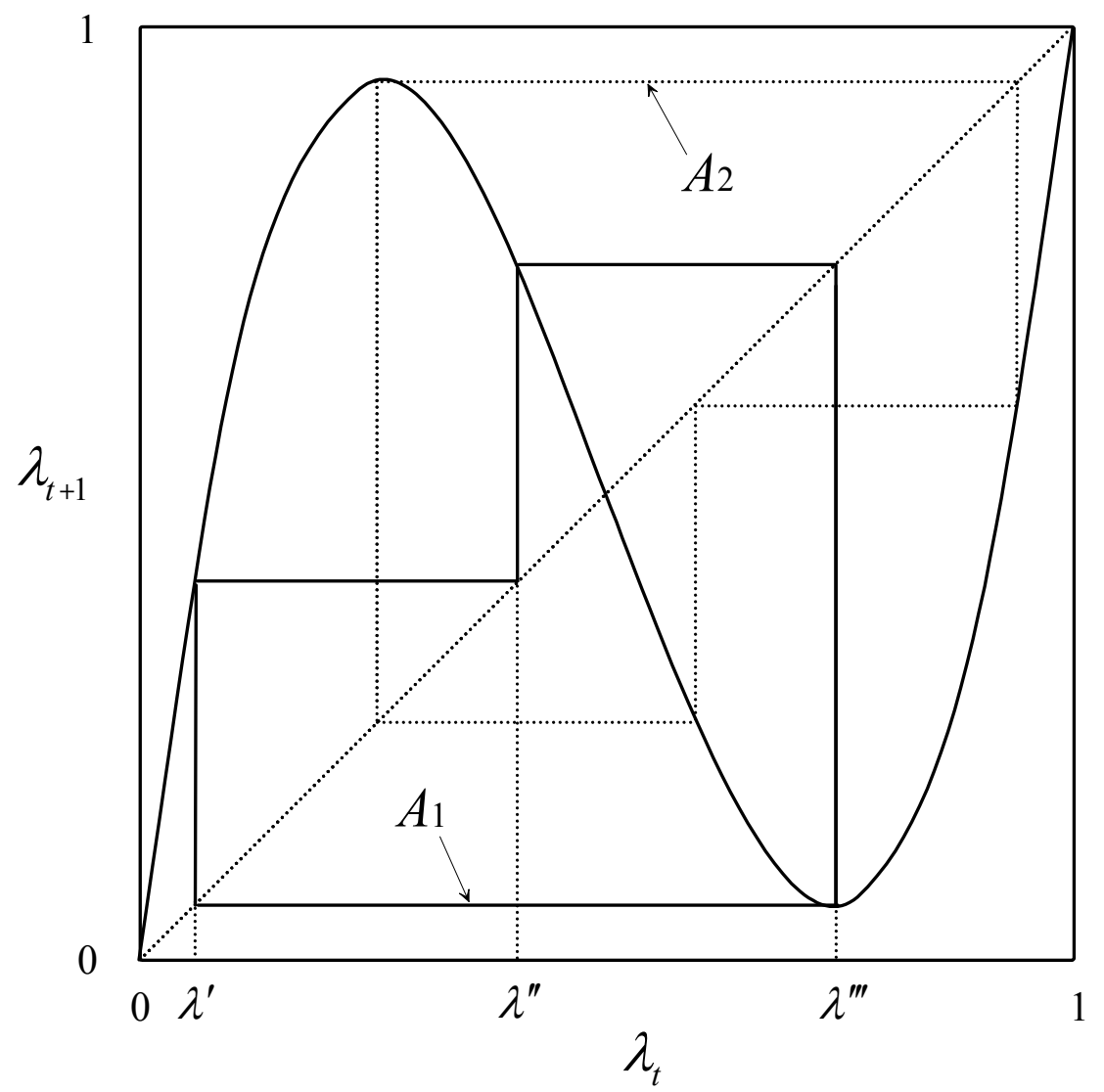

(a)

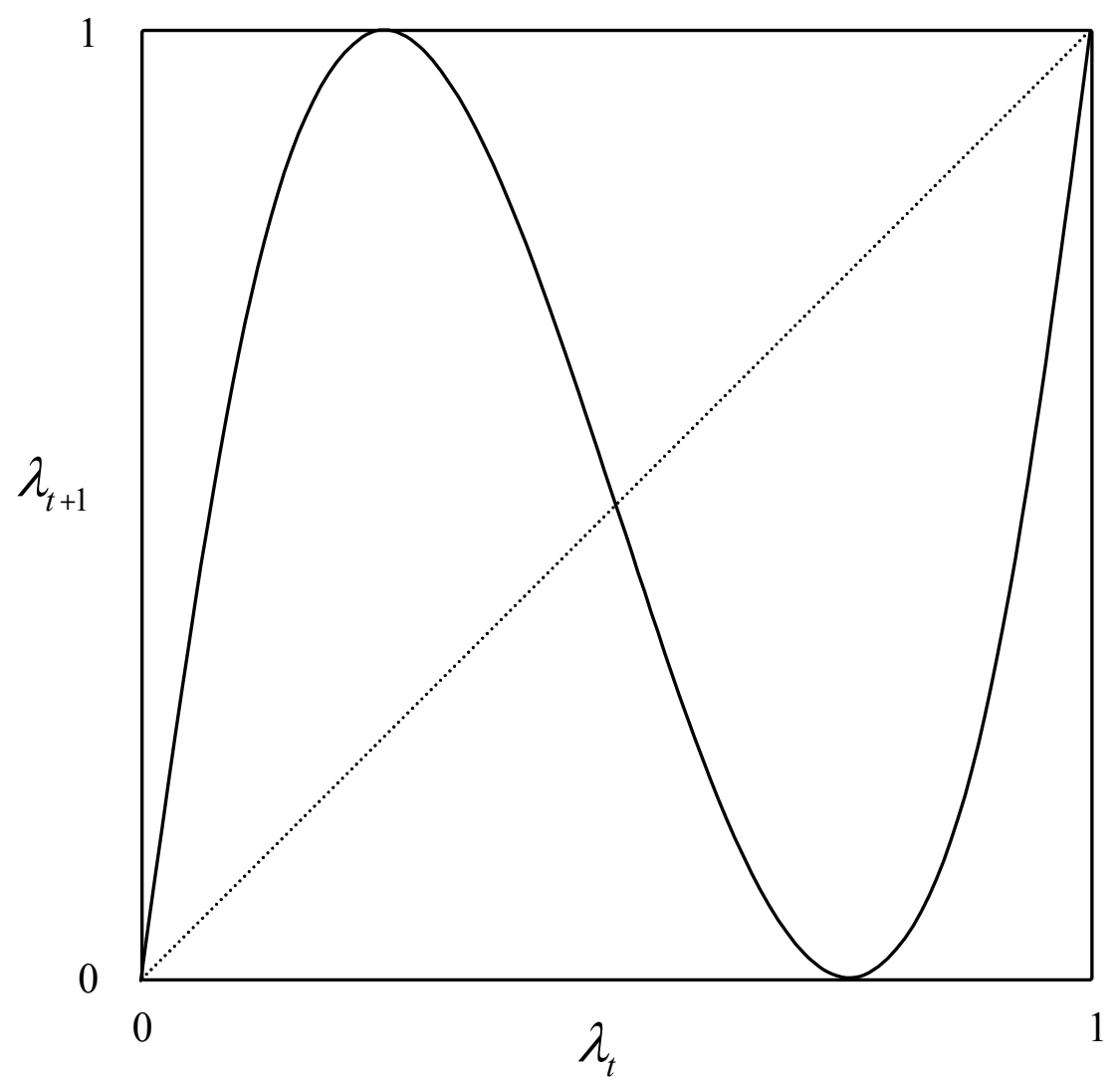

(b)

Figure 3 
minimum is 0, as in Figure 3(b). It can be shown that there exist periodic orbits of every period, and every point in [0,1] has sensitive dependence on initial conditions. ${ }^{12}$ For $\phi<\phi_{A}$, the dynamical behaviour is sufficiently volatile that, for almost all initial conditions, ${ }^{13}$ the system sooner or later converges on a core-periphery fixed point. The core-periphery fixed points themselves are unstable. If such a state were subjected to a small disturbance, the system might be attracted back to that particular fixed point or it might be attracted to the other core-periphery fixed point.

In a discrete-time framework, the migration speed $\gamma$ is potentially of crucial importance. Its impact on the system's long-term dynamical behaviour depends on whether $\phi$ is below or above $\phi_{B}$. For $\phi<\phi_{B}$, the qualitative nature of the system's long-term behaviour depends on the mobility speed. There are speeds sufficiently slow for the symmetric fixed point to be an attractor. As the speed increases, a period-doubling bifurcation occurs and further increases in speed - which 'stretch' the map $Z\left(\lambda_{t}\right)$ without altering the fixed points - give rise to orbits of every periodicity and to chaotic behaviour. There exist speeds sufficiently high that agglomeration occurs for almost all initial points. In contrast, for $\phi>\phi_{B}$, the symmetric fixed point $\lambda=1 / 2$ is unstable whatever the

\footnotetext{
${ }^{12}$ This can be shown by applying the same methods that Alligood et al. (1996, Ch. 1) use to demonstrate these properties for the logistic map $G(x)=4 x(1-x)$.

13 The initial points whose orbits do not converge on a core-periphery fixed point constitute an invariant Cantor set of points of zero measure. Identifying this set would be similar to identifying the set of points whose orbits remain in $(0,1)$ for the logistic $G(x)=\mu x(1-x)$ where $\mu>4$. On the latter, see Devaney (1989, p. 35).
} 
migration speed. The latter simply determines how rapid is the monotonic convergence on a core-periphery fixed point. ${ }^{14}$

\subsection{Comparison with the Continuous-time FE Model}

For the continuous-time $F E$ model, the instantaneous short-run general equilibrium corresponds to the short-run general equilibrium identified in Section 3. The migration process assumed by BFMOR (p. 94) is $\dot{\lambda}=\lambda(1-\lambda)\left(\omega_{1}-\omega_{2}\right)$. In fact, provided only that entrepreneurs migrate to the region with the higher real incomes, the precise specification of the migration process is irrelevant for the long-term behaviour of the continuous-time system. The only possible long-term behaviours are stationary equilibria, corresponding to fixed points in Figure 2(a). Specifically, for $\phi>\phi_{B}$, the symmetric equilibrium is unstable and only the core-periphery equilibria are stable. For $\phi<\phi_{S}$, the only stable equilibrium is the symmetric equilibrium $\lambda=1 / 2$. In the 'overlap' range, where $\phi_{S}<\phi<\phi_{B}$, the symmetric equilibrium and the core-periphery equilibria are locally stable (the interior asymmetric equilibria being unstable). BFMOR (p. 103) highlight the catastrophic agglomeration that occurs as $\phi$ increases through $\phi_{B}$ and the locational hysteresis that can result from the presence of multiple stable equilibria for $\phi>\phi_{S}$. Nevertheless, in terms of possible dynamical behaviours, the continuous-time model is manifestly much less rich than its discrete-time counter-part. The impossibility of any form of long-term asymmetric coexistence of manufacturing in both regions is particularly restrictive.

\footnotetext{
${ }^{14}$ The impact of a fall in $N$ is equivalent to the impact of a fall in the mobility speed. On the comparative dynamical effects of changes in $\sigma$ and $\mu$ in a discrete-time core-periphery model, see Currie and Kubin (2006).
} 


\section{Differential Taxation and Subsidization}

\subsection{Comparative Dynamics}

The imposition of different $\tau$ 's complicates the model dramatically. Figure 4 shows, for $\mu=0.5$, the impact of $\phi$ on the fixed points for different combinations of $\sigma$ and $\Gamma{ }^{15}$ In addition to the core-periphery fixed points, there may be $0,1,2$ or 3 interior fixed points, where $\lambda *$ is a fixed point if $\Omega(\lambda *)=1 / \Gamma$. Consider first Figure 4(a), which assumes $\sigma=4$ and a tax gap $\Gamma=0.9$, so that region 1 has the higher tax rate. A critical value for trade freeness is the sustain point $\phi_{S(2)}$ where $\Omega(0)=1 / \Gamma$, as shown in Figure 5. For $1>\phi \geq \phi_{S(2)}$, $\lambda=0$ is an attractor for any $\lambda_{0}$ in $[0,1)$, with $\lambda=1$ being unstable. As $\phi$ falls through $\phi_{S(2)}$, a bifurcation gives rise to an asymmetric interior fixed point and to the instability of $\lambda=0$. Whereas in the continuous-time $F E$ model any $\lambda_{0}$ in $(0,1)$ leads to convergence on the interior fixed point for $\phi<\phi_{S(2)}$, the discrete-time model can exhibit complex dynamical behaviour. Figure 6 shows, for region 1, the impact of trade freeness on (a) its share of manufacturing and (b) the utility of its workers. ${ }^{16}$ For $\phi \geq \phi_{S(2)}$, agglomeration occurs in region 2. For a given trade freeness, this is the worst outcome for region 1's workers who, receiving nothing from the government and having to import all their consumption of manufactures, have a utility of $u_{P}$, as in (16). For $\phi_{P} \leq \phi<\phi_{S(2)}$, the system is attracted to the asymmetric interior fixed point. For $\phi_{A} \leq \phi<\phi_{P}$, long-term behaviour is periodic or

${ }^{15}$ BFMOR (p. 107) and Forslid and Ottaviano (2003) present a 'broken tomahawk' for their continuous-time FE model with regional asymmetry.

${ }^{16}$ Figure 6 assumes $\sigma=4, \mu=0.5, N=100, \gamma=0.1, \beta=1, \tau_{1}=0.1, \tau_{2}=0$ and $\lambda_{0}=0.5$. 

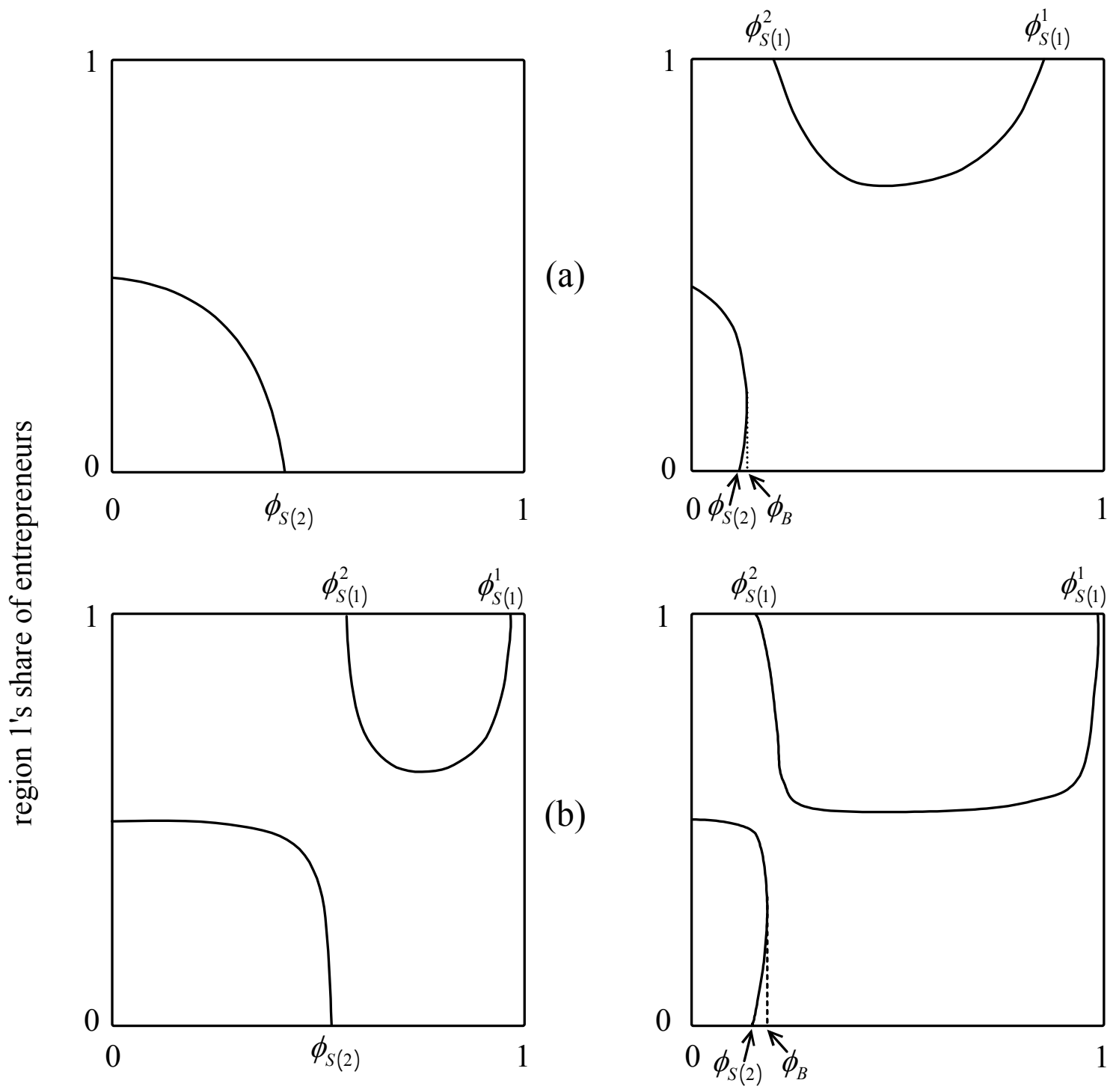

(c)

(b)

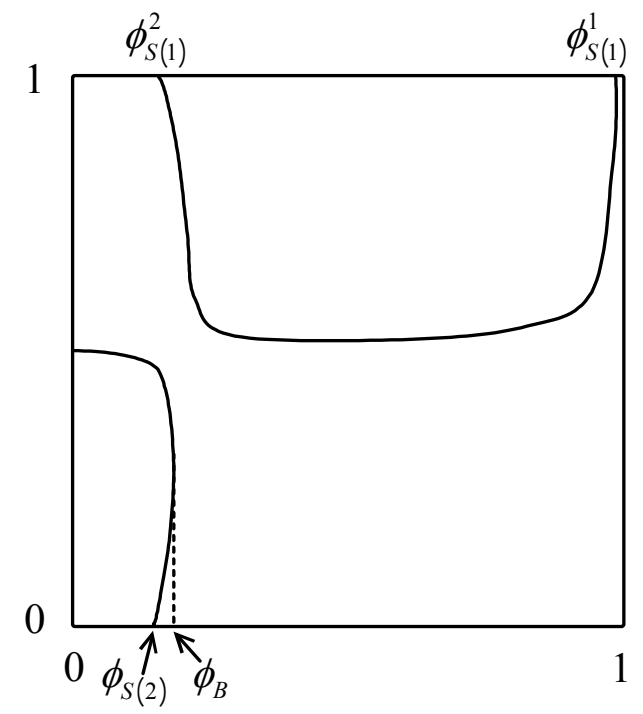

(d)

trade freeness

Figure 4 


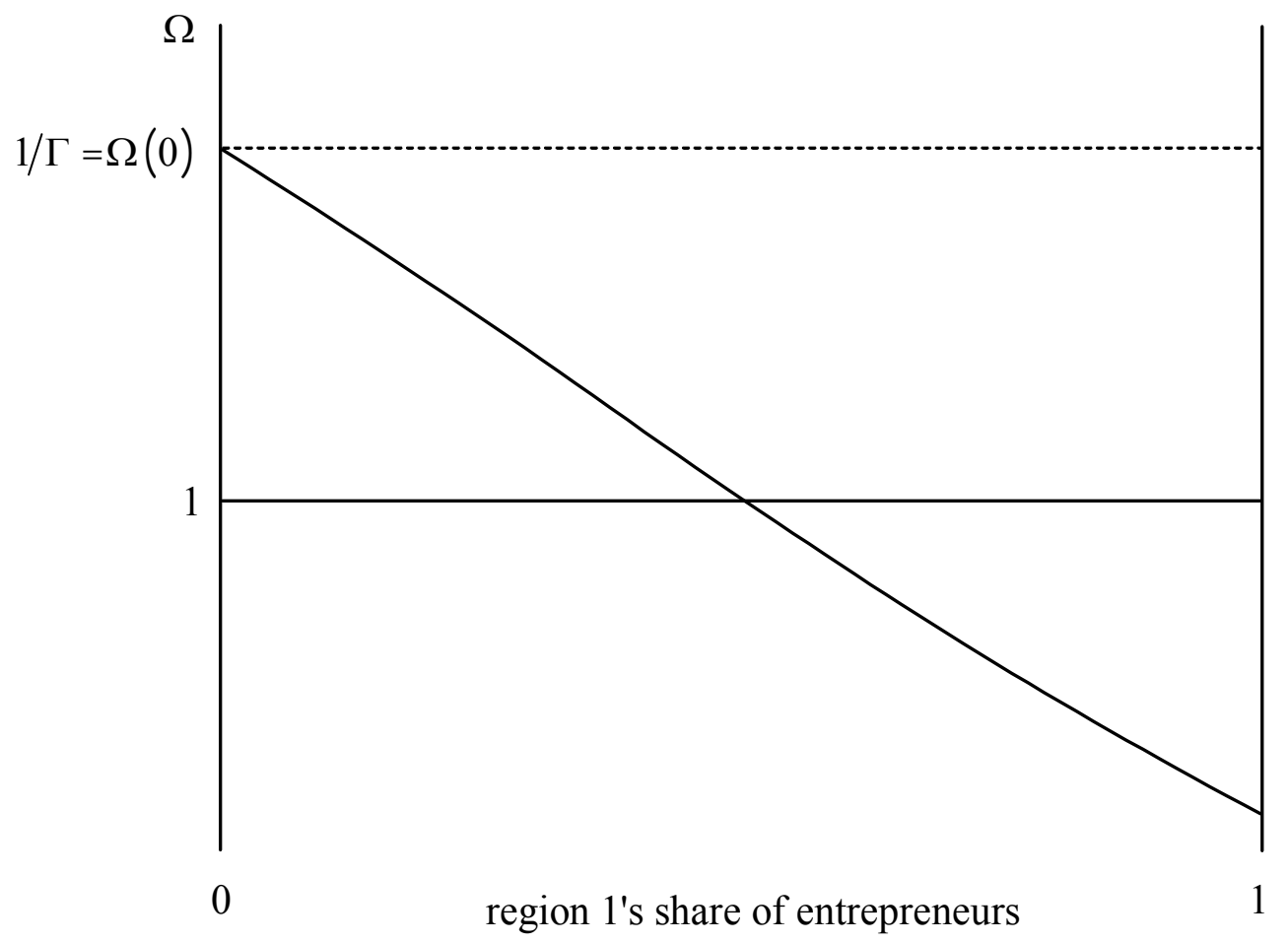

Figure 5 


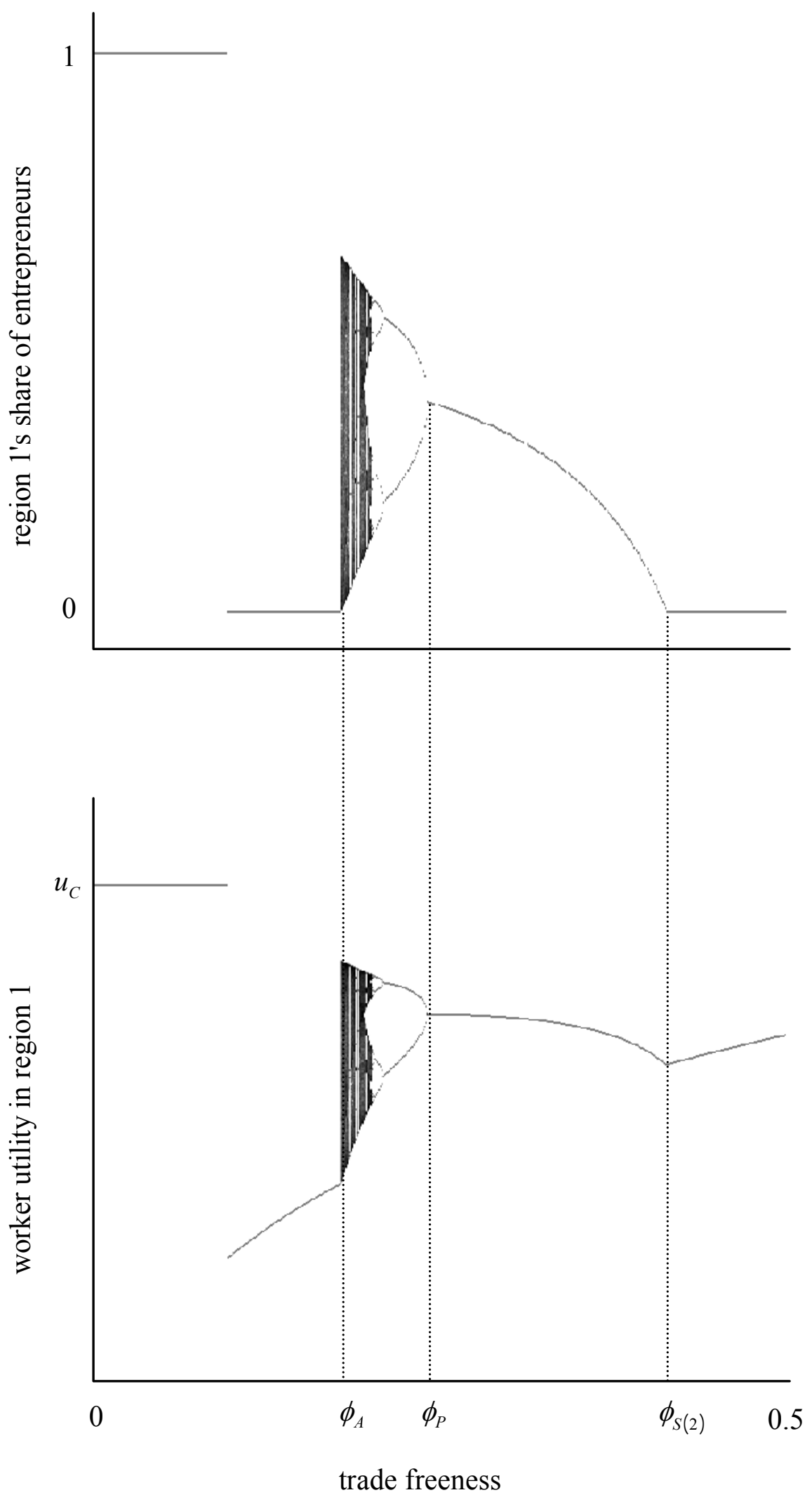

(a)

(b)

Figure 6 
chaotic. In Figure 7, which shows the type of asymmetry of $Z\left(\lambda_{t}\right)$ that results from region 2 having the lower tax rate, $A$ is a period-3 attractor for almost all initial points satisfying $0<\lambda_{0}<\lambda_{a}$ and for their pre-images of any rank. Agglomeration in region 2 occurs (immediately) for all initial points in $\left[\lambda_{a}, \lambda_{b}\right]$ and (eventually) for their preimages of any rank. For $\phi<\phi_{A}$, volatility results in agglomeration for $\lambda_{0}=0.5$ (as assumed in Figure 6). ${ }^{17}$ Depending on whether region 1 becomes the periphery or the core, worker utility is given by $u_{P}$ or by $u_{C}$, as in (15).

Reducing the tax gap to $\Gamma=0.99$, as in Figure 4(b), results in the emergence of two sustain points for region 1 , i.e., $\Omega(1)=1 / \Gamma$ at both $\phi_{S(1)}^{1}$ and $\phi_{S(1)}^{2}$. The curve between these points is a locus of unstable fixed points. For $\phi_{S(1)}^{2}<\phi<\phi_{S(1)}^{1}$, agglomeration occurs in the high-tax region 1 for any $\lambda_{0}$ above that curve, with $\lambda=1$ being locally stable, and it occurs in the low tax region 2 for any $\lambda_{0}$ below that curve, with $\lambda=0$ being locally stable. For $1>\phi>\phi_{S(1)}^{1}$ and for $\phi_{S(2)} \leq \phi<\phi_{S(1)}^{2}$, the attraction of the lower tax rate always prevails, with agglomeration occurring in region 2 for any $\lambda_{0}$ in $(0,1)$.

In Figure 4(c), which assumes $\sigma=2$ and $\Gamma=0.9, \phi_{B}$ constitutes a break point at which an interior asymmetric fixed point $\lambda^{*}$ arises where $\Omega^{\prime}(\lambda *)=0$. Figure 8 shows $\Omega\left(\lambda_{t}\right)$ for $\phi=\phi_{B}$. As $\phi$ falls through $\phi_{B}$, a fold bifurcation gives rise to two asymmetric interior fixed points, corresponding to points on the curved branches. The lower branch,

\footnotetext{
${ }^{17}$ There is not a simple characterization of $\phi_{A}$ in terms of $Z\left(\lambda_{t}\right)$ (in contrast to the case of regional symmetry in Figure 3(b)).
} 


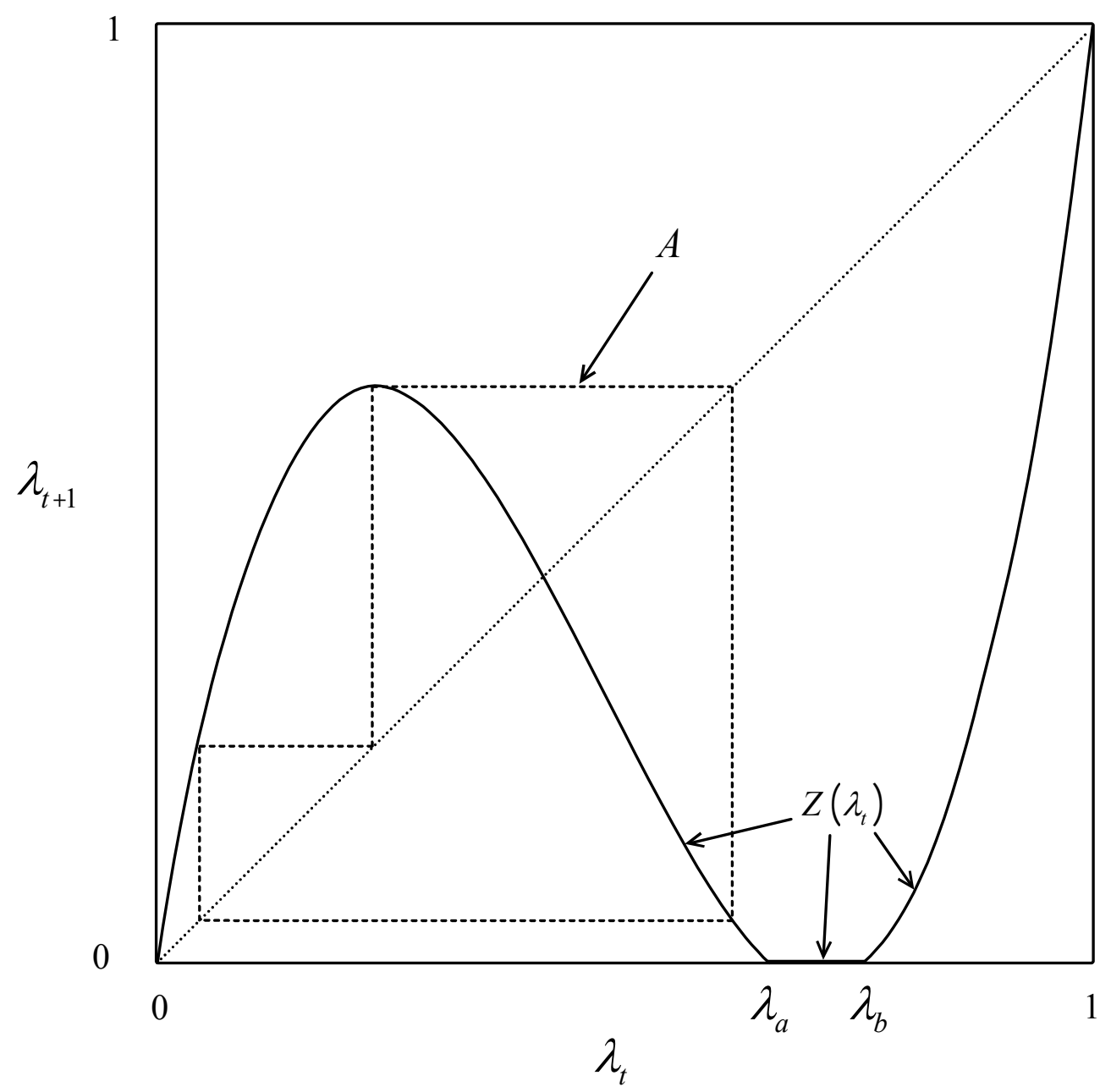

Figure 7 


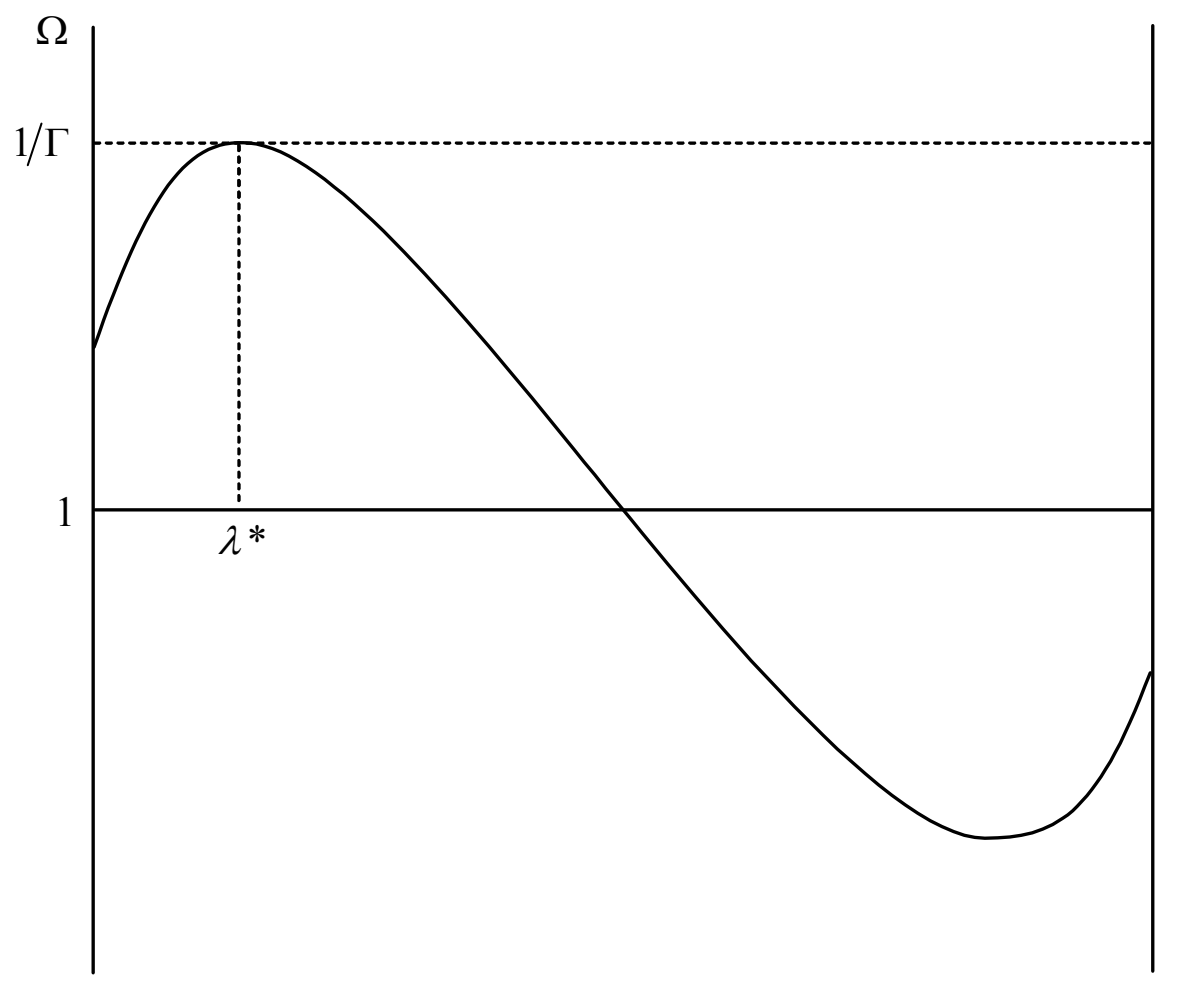

region 1's share of entrepreneurs

Figure 8 
which ends at $\phi_{S(2)}$, is a locus of unstable fixed points. Reducing the tax gap increases the break point: as $\Gamma \rightarrow 1, \phi_{B} \rightarrow \phi_{B(\Gamma=1)}$, where $\phi_{B(\Gamma=1)}$ denotes the break point with $\Gamma=1$ and where $\phi_{B(\Gamma=1)}$ corresponds to $\phi^{\prime}$ in Figure 1(b). In Figure 4(d), with a lower tax gap $\Gamma=0.99$, there is a range $\phi_{S(1)}^{2}<\phi<\phi_{B}$ for which there are three interior fixed points, of which the outer two are necessarily unstable.

The differences between the continuous-time and discrete-time models arise for a trade freeness, $\phi<\phi_{B(\Gamma=1)}$. For their continuous-time model, BFMOR note that, starting at a symmetric equilibrium, the effects of tax changes are "quite neoclassical in the sense that a marginal tax change gives a marginal relocation of the mobile factor" (p. 380). The one exception that they highlight is the possibility that, beyond a point, changing, say, $\tau_{1}$ may lead abruptly to agglomeration. Consider Figure 9, a case of 'intermediate' trade freeness. Starting at $\Gamma=1$, gradually reducing $\tau_{1}$, which lowers $1 / \Gamma$, initially increases region 1 's share of manufacturing continuously. However, catastrophic agglomeration occurs as $1 / \Gamma$ falls through $1 / \Gamma_{B(2)}$, where $\Gamma_{B(2)}$ is what BFMOR call the 'break-point tax gap'. ${ }^{18}$

In contrast, in our discrete-time $F E$ model, it is the exception for the effects of tax changes to be 'neoclassical'. For the properties of the continuous-time FE model to carry over, entrepreneurs have to be sufficiently 'slow' in their responsiveness to differences in post-tax real incomes. Where the mobility speed is such that the system exhibits complex dynamical behaviour, the hyper-sensitivity to parameters means that there are endless possibilities for small tax changes to have abrupt and dramatic effects. Based on the same

\footnotetext{
${ }^{18}$ If trade freeness is sufficiently low that $\Omega\left(\lambda_{t}\right)$ is monotonically declining throughout, as in Figure 1(e), there is no such abrupt shift to agglomeration in a continuous-time model.
} 


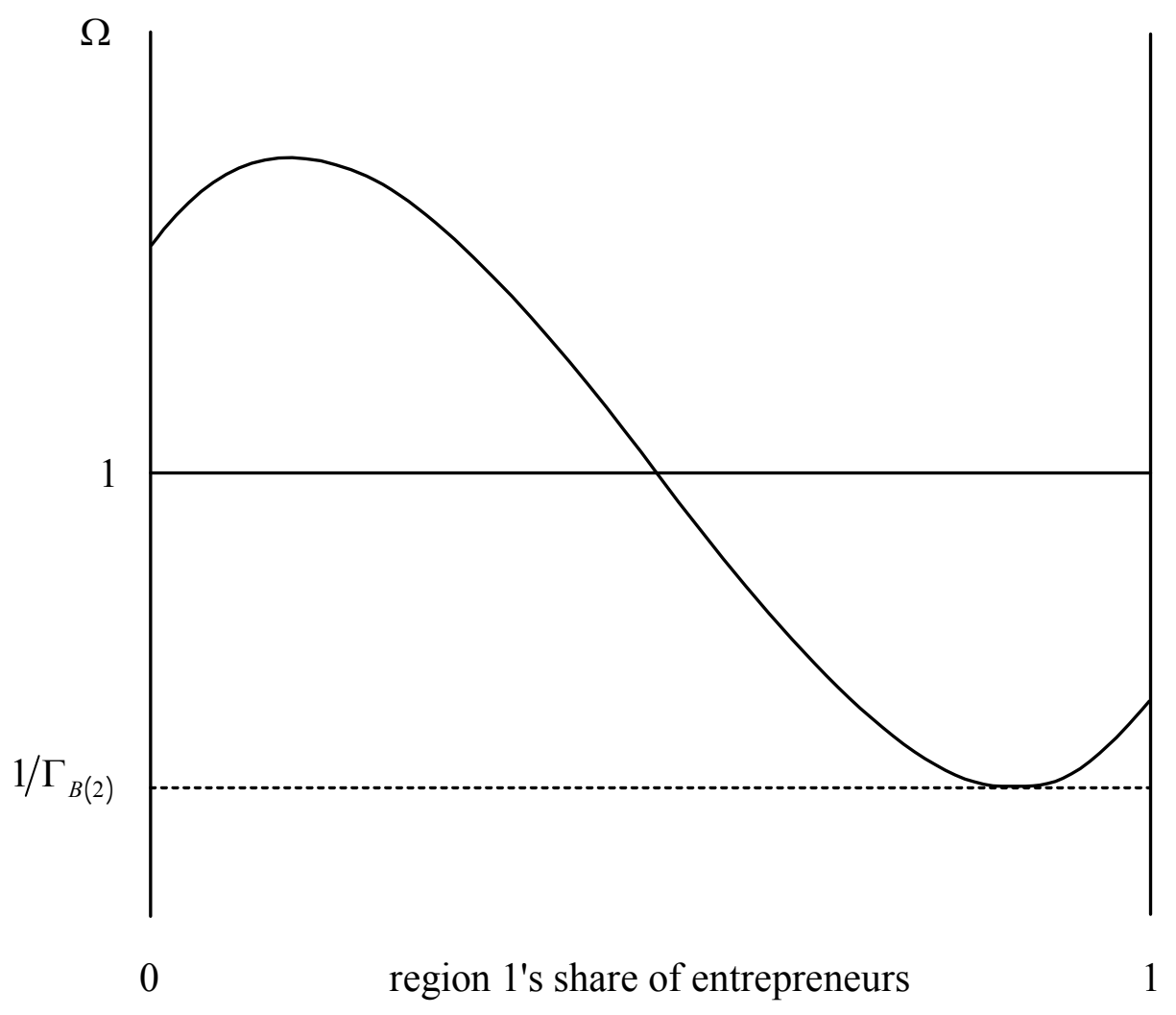

Figure 9 
$\sigma, \mu, \gamma, N$ and $\phi$ as Figure 3(a) and assuming $\tau_{2}=0$, Figure 10 shows the impact of $\tau_{1}$ on the system's behaviour over the range $-0.008<\tau_{1}<0.008$. Assuming that the system is initially following the period-3 orbit $A_{2}$ in Figure 3(a), ${ }^{19}$ very small departures from $\tau_{1}=0$ could result in agglomeration, periodic cycles or chaotic behaviour. Where behaviour is chaotic at the new tax rate, predicting the orbit beyond a very limited time horizon would be meaningless. Furthermore, sensitive dependence on initial conditions implies that the impact of a tax change can depend on the precise timing, since that determines the "initial condition' for the new orbit. Indeed, a purely temporary tax change could have a long-term effect. For example, given that the system is initially following orbit $A_{2}$, depending both on precisely when the tax rate is changed and on precisely when it is restored to its initial level, the system could be attracted to the period-3 orbit $A_{1}$. In that particular case, there would be a shift from the orbit that favours region 1 workers to the orbit that favours region 2 workers.

Where agglomeration occurs through volatility, which region becomes the core is highly sensitive to the precise levels both of the tax gap and of trade freeness. This is confirmed in Figures 11(a) and 11(b), which show, for $(\phi, \Gamma)$ combinations over the ranges $0<\phi \leq 0.2$ and $0.8 \leq \Gamma \leq 1.2$, the system's behaviour after the elapse of 1000 periods assuming initial conditions $\lambda_{0}=0.5$ and $\lambda_{0}=0.9$, respectively. ${ }^{20}$ In the grey regions, longterm behaviour is stationary, periodic or chaotic. In contrast, agglomeration has occurred in region 1 for $(\phi, \Gamma)$ combinations in the black regions and in region 2 for $(\phi, \Gamma)$ combinations in the white regions.

\footnotetext{
${ }^{19}$ Specifically, Figure 10 assumes $\lambda_{0}=1-\lambda^{\prime \prime}$, which is a point on orbit $A_{2}$.

${ }^{20}$ Figure 11 assumes the same $\sigma, \mu, N$ and $\gamma$ as in Figure 6.
} 


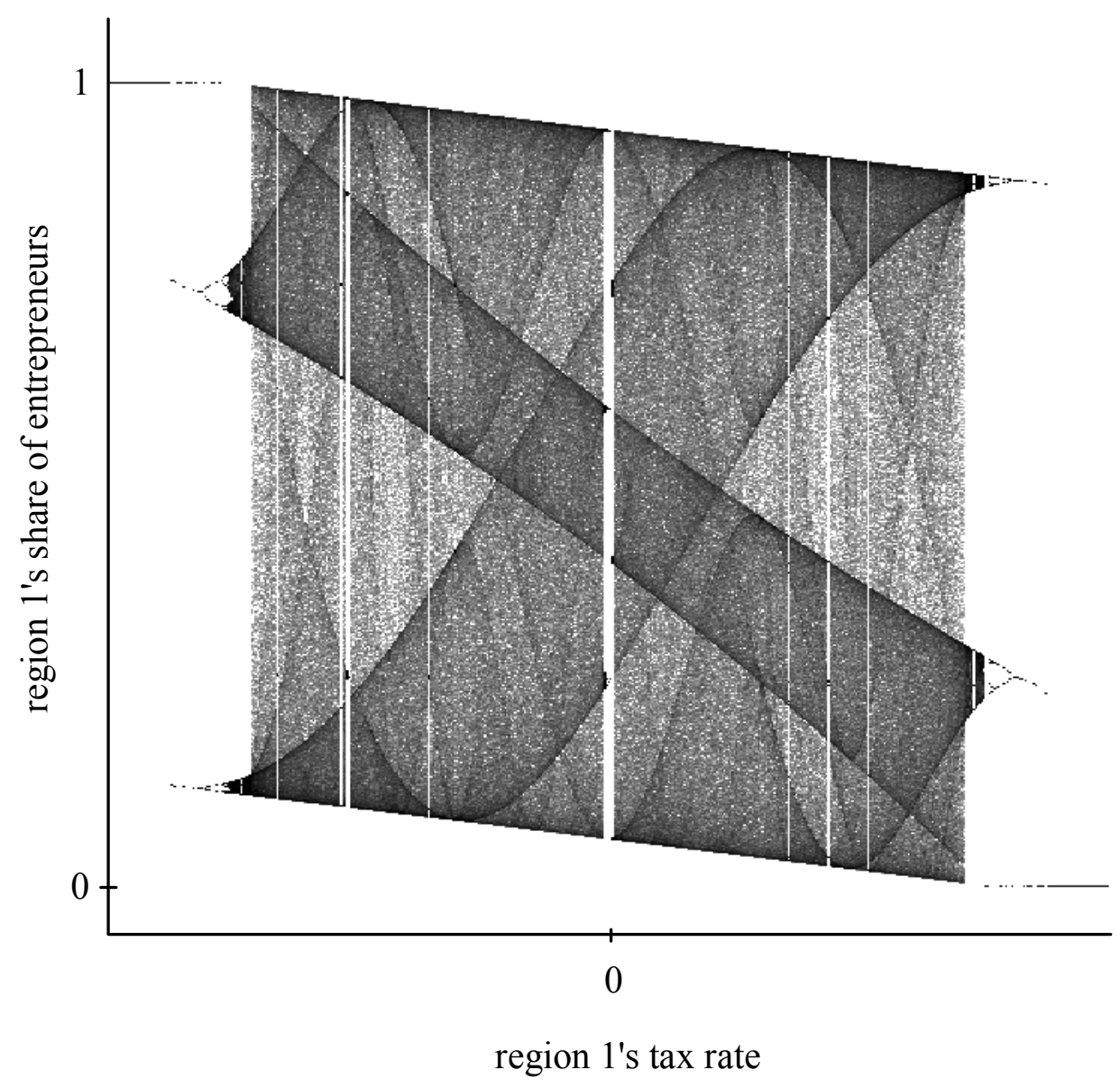

Figure 10 


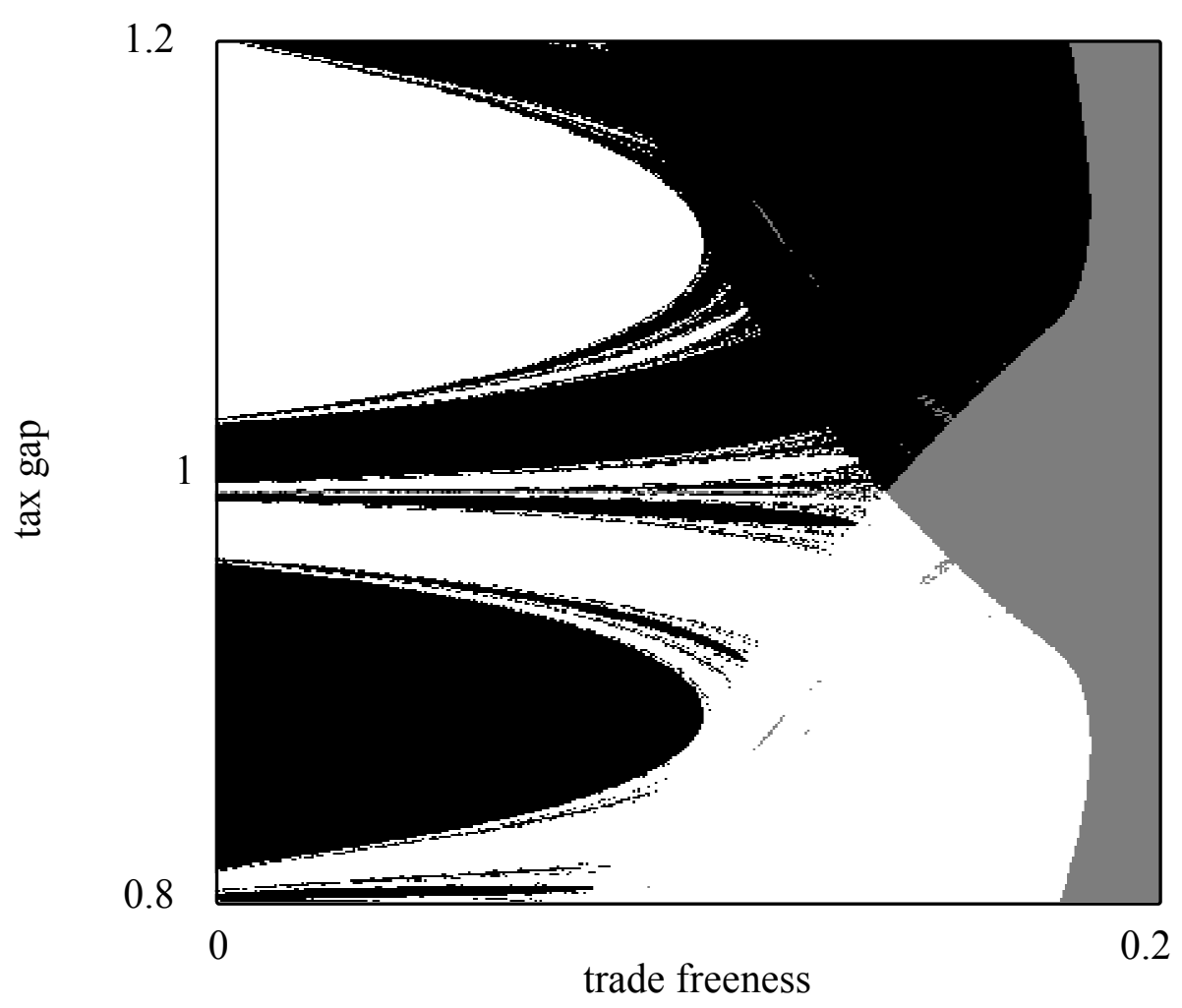

(a)

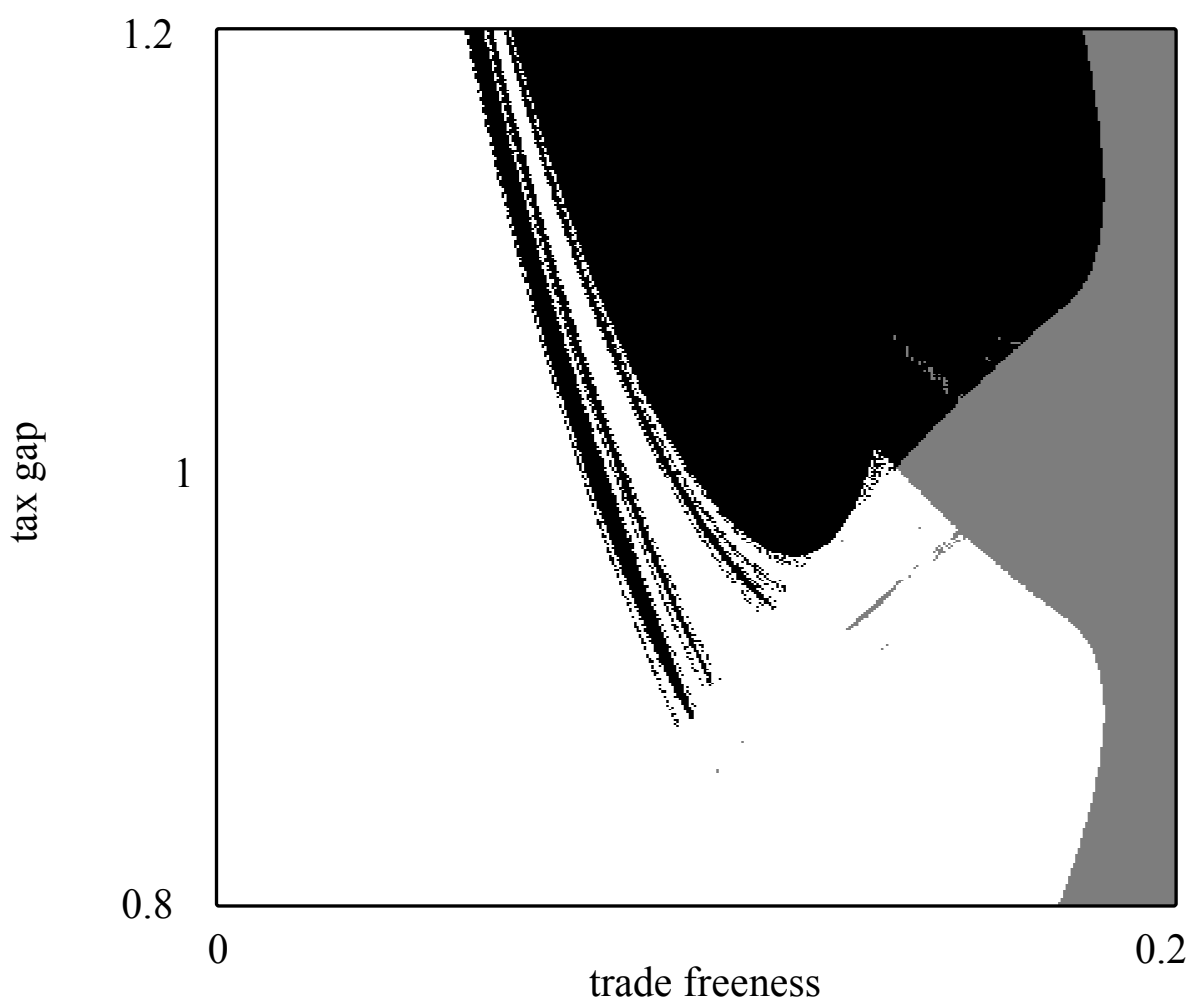

(b)

Figure 11 


\subsection{Choice of Tax or Subsidy}

A government can use the tax rate as a policy instrument to influence worker utility. Starting with a uniform tax rate $\bar{\tau}_{1}=\bar{\tau}_{2}$ (which could be positive, zero or negative), consider government 1's choice of a new rate, holding region 2's rate constant at $\bar{\tau}_{2}$. Choosing a new $\tau_{1}$ is equivalent to choosing a new tax gap. The impact of the choice depends crucially on the freeness of trade. Moreover, as BFMOR (p. 374) emphasize, it matters greatly where one starts. In their continuous-time model, the initial position may be an agglomerated equilibrium or the symmetric equilibrium; for our discrete-time model, the initial situation could also involve periodic or chaotic behaviour.

Consider first the case of a 'high' trade freeness, $\phi>\phi_{B(\Gamma=1)}>\phi_{S(\Gamma=1)}$, where $\phi_{S(\Gamma=1)}$ is the sustain point with uniform tax rates. The system would be attracted to a core-periphery fixed point both before and after the change in $\tau_{1}$. Since $\phi>\phi_{S(\Gamma=1)}$ implies $\Omega(0)<1$ and $\Omega(1)>1, \quad \lambda=0$ and $\lambda=1$ are locally stable at $\Gamma=1$. Initially, suppose that all manufacturing is already concentrated in region 1. In this situation, it is possible to benefit workers in region 1 by an increase in $\tau_{1}$. For region 1 to retain all the manufacturing, the new tax gap must satisfy $\Gamma \Omega(1) \geq 1$. Since, for a given location of entrepreneurs, worker utility increases with the tax rate, the optimal tax rate is the maximum tax rate consistent with the retention of all the manufacturing. ${ }^{21}$ BFMOR define the 'sustain-point tax gap' for region 1 as

\footnotetext{
${ }^{21}$ It should be acknowledged that there is a tension between the identification of this maximum tax rate and the mobility hypothesis. The latter, via (20) and (21), implies that entrepreneurs never move to a region with no manufacturing in the previous period - an assumption that is common to BFMOR's model and, indeed, to all continuous-time core-periphery models. Taking this literally would imply that, once a region had all the
} 


$$
\Gamma_{S(1)}=\frac{1}{\Omega(1)}
$$

Figure 12 identifies $1 / \Gamma_{S(1)}$. The corresponding tax rate would be

$$
\hat{\tau}_{1}=1-\left(1-\bar{\tau}_{2}\right) \Gamma_{S(1)}=1-\frac{1-\bar{\tau}_{2}}{\Omega(1)}
$$

That is, $\hat{\tau}_{1}$ is the maximum tax rate consistent with retaining all manufacturing. From (26), $\Omega(1)>1$ implies that $\hat{\tau}_{1}>\bar{\tau}_{2}$. This is the case highlighted by BFMOR: the government in region 1 is able to tax the location-specific rents created by agglomeration forces without provoking an exodus of manufacturers. ${ }^{22}$

$B F M O R$ frequently use the hump-shaped relationship between $\Omega(1)$ and $\phi$, as given by $(18) .{ }^{23}$ In Figure 13, for a given $1 / \Gamma$, the curve identifies the sustain-point trade freeness levels for region 1. Since Figure 13 assumes $\breve{\Gamma}=0.9, \mu=0.5$ and $\sigma=2, \breve{\phi}$ and $\phi$ correspond, respectively, to $\phi_{S(1)}^{1}$ and $\phi_{S(1)}^{2}$ in Figure 4(c). Conversely, for a given trade freeness, the curve identifies the reciprocal of the corresponding sustain-point tax gap. Thus $\breve{\Gamma}$ would be the sustain-point tax gap corresponding to both $\breve{\phi}$ and $\phi$. It should be stressed that setting the sustain-point tax gap would be, to say the least, precarious. It means that an entrepreneur contemplating moving to the periphery would have no positive incentive to do

manufacturing, the only constraint on taxing entrepreneurs would be the threat that they might give up being entrepreneurs altogether. Therefore, we need to assume that, in a core-periphery state, there is a positive probability that some entrepreneur would contemplate a move to the periphery.

22 See their Result 15.2.

${ }^{23}$ Properties of the relationship are: (i) $\Omega(1)=1$ when $\phi=1$; (ii) $\Omega(1) \rightarrow 0$ as $\phi \rightarrow 0$; (iii) $\Omega(1)$ is maximized at $\phi=\sqrt{\phi_{B(\Gamma=1)}}$. 


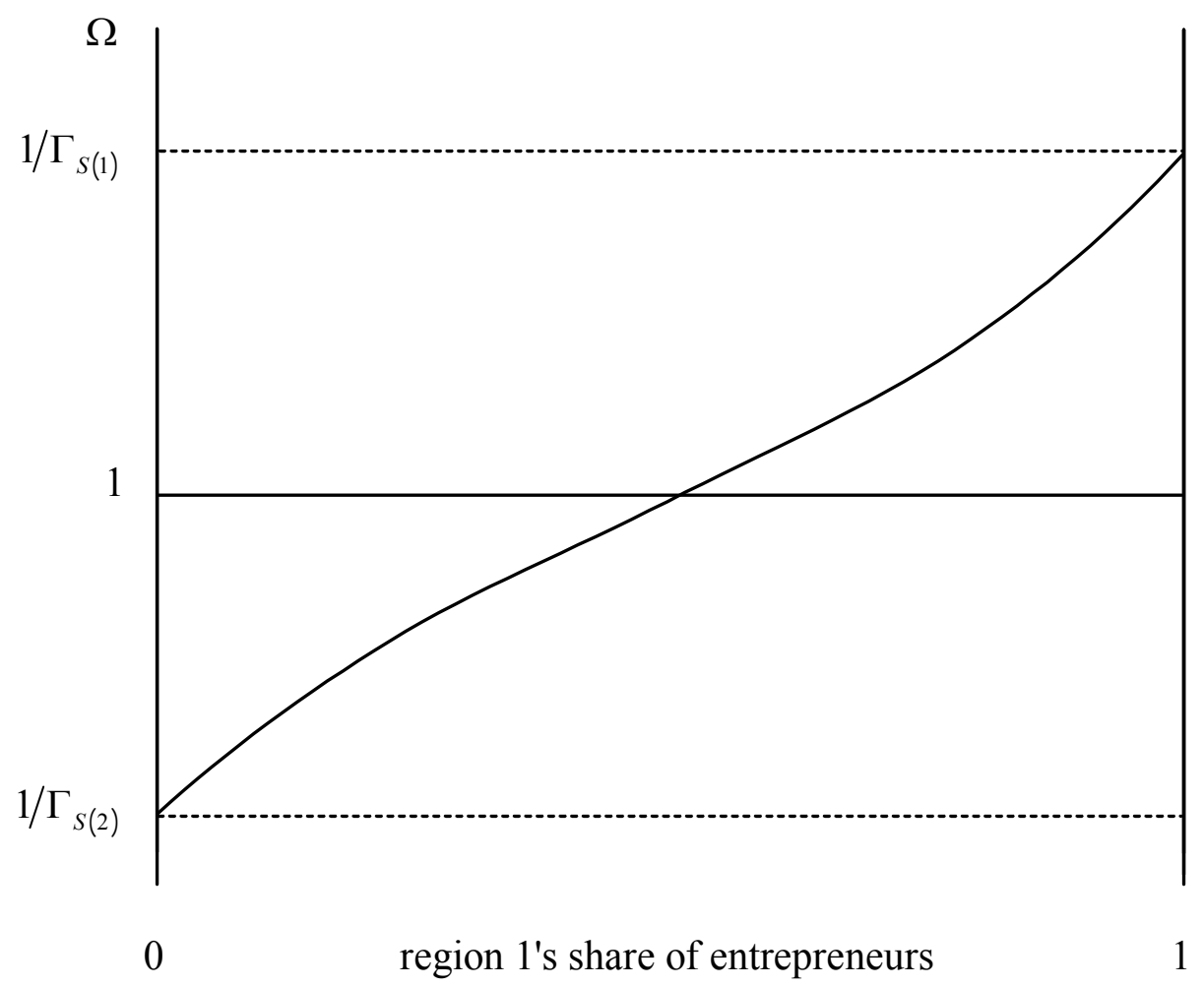

Figure 12 


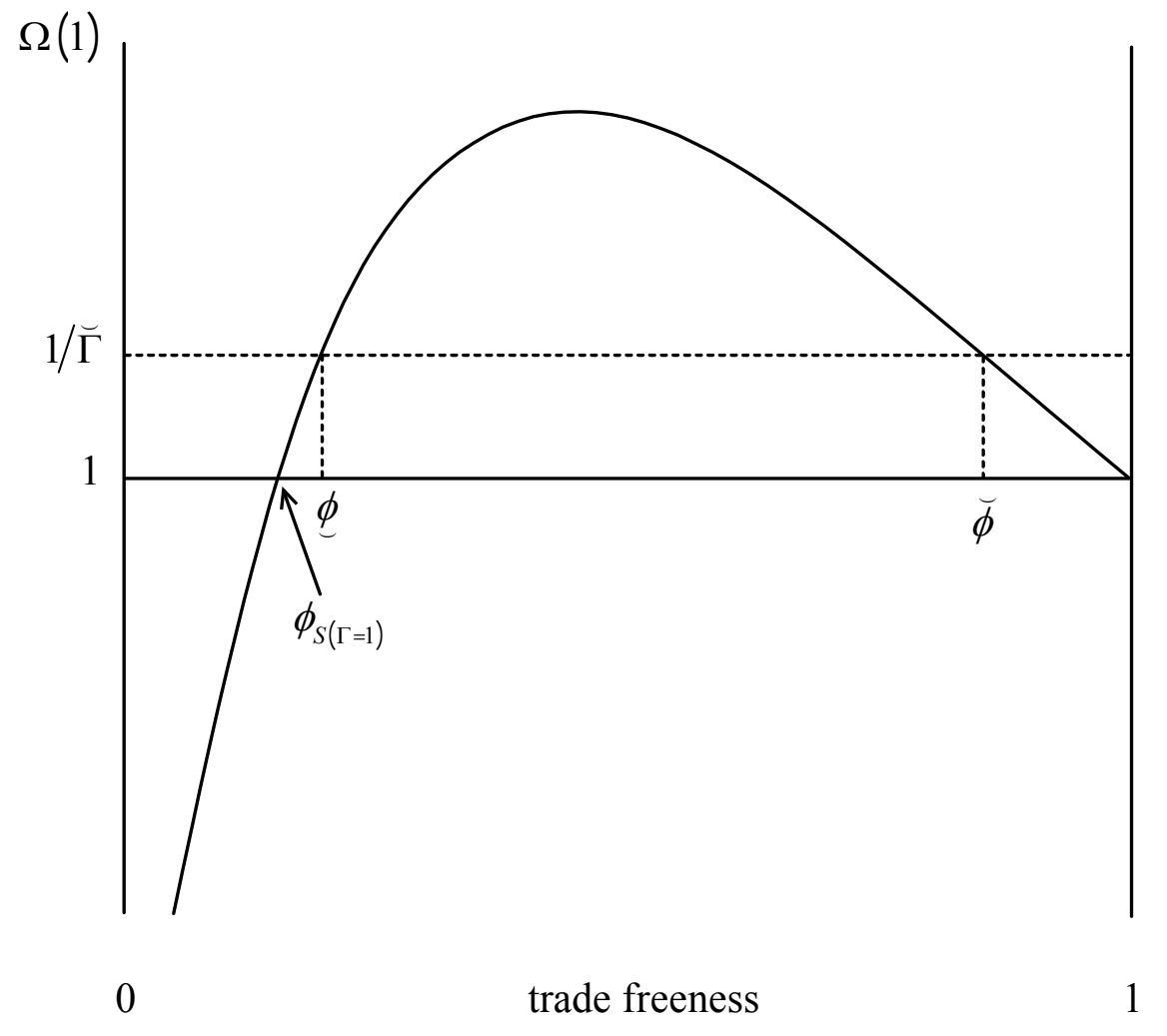

Figure 13 
so [i.e., $\breve{\Gamma} \Omega(1)=1$ ]. However, if, for whatever reason, one did actually move, this would create positive incentives for others to follow. In other words, it is inherent in setting the sustain-point tax gap that $\lambda=0$ is an attractor for any $\lambda_{0}$ in $[0,1)$. Moreover, a slight miscalculation by the government could result in $\Gamma \Omega(1)<1$, leading to a catastrophic shift of manufacturing to the other region. Note the importance of the direction of any miscalculation. If the true $\phi$ is just below $\phi$ or if the true $\phi$ is just above $\breve{\phi}$, setting a tax gap of $\breve{\Gamma}$ would lead to the exodus of all manufacturing.

Suppose instead that all manufacturing is initially concentrated in region 2 , with $\lambda=0$ being locally stable for $\Gamma=1$. For region 1 to attract all the manufacturing, the new tax gap must satisfy $\Gamma \Omega(0)>1$. This would require a tax rate strictly below

$$
\tilde{\tau}_{1}=1-\left(1-\bar{\tau}_{2}\right) \Gamma_{S(2)}=1-\frac{1-\bar{\tau}_{2}}{\Omega(0)}=1-\left(1-\bar{\tau}_{2}\right) \Omega(1)
$$

where $\Gamma_{S(2)}=1 / \Omega(0)$ is the sustain-point tax gap for region 2 . Figure 12 identifies $1 / \Gamma_{S(2)}$. From (27), $\Omega(0)<1$ implies $\tilde{\tau}_{1}<\bar{\tau}_{2}$. If region 1 can attract all manufacturing with a positive tax rate, it must benefit its workers to do so. However, attracting all manufacturing away from the other region may require a subsidy. In that event, the cost to region 1's workers might be less than the benefits to them from doing so. For region 1's workers to benefit from attracting all manufacturing via a subsidy, worker utility in the core at $\tau_{1}$ must exceed worker utility in the periphery. From (15) and (16), the level of $\tau_{r}$ at which worker utility is the same whether region $r$ is the core or the periphery is given by

$$
\underset{\sim}{\tau}=\left(\phi^{\frac{\mu}{\sigma-1}}-1\right) \frac{\sigma-\mu}{2 \mu}
$$


where $\underset{\sim}{\tau}<0$. That is, with a subsidy rate of $|\underset{\sim}{\tau}|$, workers in region 1 would be indifferent between their region being the core or the periphery. Thus, both for region 1 to become the core and for its workers to benefit, the new rate $\tau_{1}$ must satisfy $\underset{\sim}{\tau}<\tau_{1}<\tilde{\tau}_{1}$. This is subject to a qualification: there may be another possible strategy for government 1 . Provided that it were confident of no reaction by government 2 to the exodus of its entrepreneurs, the optimal strategy for government 1 could involve two stages. It would first set a tax / subsidy rate just sufficient to attract all the manufacturing from region 2 . Once all manufacturing has relocated to region 1, it could raise the tax rate [up to a limit of $\hat{\tau}_{1}$, as given by (26)].

The situation is potentially much more complex where $\phi<\phi_{B(\Gamma=1)}$. This is partly because, for our discrete-time model, the initial situation could involve agglomeration in either region, a symmetric equilibrium or complex dynamical behaviour. If $\phi>\phi_{S(\Gamma=1)}$, an initial core-periphery state $\lambda=1$ would be locally stable and the tax gap could, in principle, be raised up to the sustain point tax gap. In contrast, if $0<\phi<\phi_{S(\Gamma=1)}$, an initial coreperiphery state $\lambda=1$ would be unstable, with $\Omega(1)<1$ at $\Gamma=1$. An increase in $\tau_{1}$ would make a move from the core to the periphery even more attractive. If some entrepreneur does move, this might result in a catastrophic shift of all manufacturing to the other region (though the system might snap back to $\lambda=1$ ). In other words, in the discrete-time model, the fact that all industry is initially concentrated in region 1 certainly does not imply a prima facie case for attempting to tax agglomeration rents. Indeed, the best strategy might be for the government in region 1 to reduce its tax rate (or increase the subsidy rate) in order to make $\lambda=1$ stable. If the initial core-periphery state involves $\lambda=0$, the case for government 1 reducing its tax rate would be even stronger. This would increase the 
likelihood of inducing entrepreneurs to move from the other region and would enhance the prospect of retaining them if they do move.

If the initial system behaviour is periodic or chaotic, the minimum rate $\tau_{1}$ needed to induce agglomeration in region 1 may not be well-defined. For example, in Figure 10, there is not a sharp distinction between tax rates for which agglomeration in region 1 does occur and rates for which it does not occur.

\subsection{Observations on Tax and Subsidy Competition}

It is unlikely that a government would passively accept an exodus of entrepreneurs engineered by the government in the other region. What if there is active competition, with both governments attempting to attract or retain entrepreneurs? Given the endless possibilities for dynamical behaviour and given that a government might contemplate a strategy involving, say, a temporary tax fall followed by a permanent tax increase, the 'tax game' is potentially so complex that a formal game-theoretic treatment is certainly beyond the scope of this paper. Instead, we confine ourselves here to suggesting some possibilities.

For a high trade freeness $\phi>\phi_{B(\Gamma=1)}$, ruling out complex strategies involving, say, planned temporary cuts in $\tau_{r}$, we could envisage an equilibrium in which manufacturing is concentrated in one region and it would not benefit the workers in the other region for its government to offer the subsidy needed to attract all the manufacturing. The nature and interpretation of such an equilibrium depends on the timing of government decisions. Suppose that the historical development has been such that region 2 is the core. Assuming initially that the governments set tax rates simultaneously and non-cooperatively in each period, for government 1 to set $\tau_{1}=\underset{\sim}{\tau}<0$, as given by (28), and for government 2 to set 
$\tau_{2}=1-(1-\underset{\sim}{\tau}) \Omega(0)$ would constitute a Nash equilibrium in the following sense. Given $\tau_{2}=1-(1-\underset{\sim}{\tau}) \Omega(0)$, it would not pay region 1 to deviate, in that any subsidy greater than $|\underset{\sim}{\tau}|$ would harm workers in region 1 . Given $\tau_{1}=\underset{\sim}{\tau}$, it would not pay government 2 to deviate, since it is offering the lowest subsidy (or changing the highest tax) consistent with retaining the core. Alternatively, suppose that in each period government 2 is the 'leader' and government 1 is the 'follower'. ${ }^{24}$ In that case, possessing the requisite information, government 2 would set $\tau_{2}=1-(1-\underset{\sim}{\tau}) \Omega(0)$, since it knows that any lower subsidy (higher tax) would provide government 1 with the opportunity to attract entrepreneurs away. ${ }^{25}$ Whatever the assumed timing, our earlier caveat should be recalled. That is, an equilibrium involving $\tau_{2}=1-(1-\underset{\sim}{\tau}) \Omega(0)$ would be a precarious one: an entrepreneur contemplating moving to the periphery would have no positive inducement to do so, but, if one did move, this would create positive inducements for others to follow.

If $\phi_{S(\Gamma=1)}<\phi<\phi_{B(\Gamma=1)}$, since the core-periphery states are locally stable at $\Gamma=1$, one could again envisage such a state being an equilibrium in which it would not benefit the workers in the periphery for its government to offer the subsidy needed to undermine that state. But there are other possibilities. For example, for an intermediate trade freeness $\phi_{P(\Gamma=1)}<\phi<\phi_{B(\Gamma=1)}$, even without overt government cooperation, a situation of uniform tax

\footnotetext{
${ }^{24}$ It is beyond the scope of this paper to compare our model to the tax competition model used by Krugman and Baldwin (2004), which forms the basis of BFMOR's Ch. 16.6. However, we should note that they assume a similar Stackelberg-type sequence and that they focus on trade freeness levels sufficiently high for coreperiphery states to be stable.

${ }^{25}$ Whether tax rates are set simultaneously or in sequence, the timing of decisions within the elementary time period does not matter. Given that entrepreneurs move at the transitions between periods, the tax rates set in period $t$ determine that period's post-tax real incomes and the ratio of the latter determines the migration at the transition to period $(t+1)$.
} 
rates with a stable symmetric equilibrium could conceivably persist if both governments recognize that a tax war could well be harmful to both regions. Thus there could be a stable situation akin to that for an infinitely-repeated prisoners' dilemma game where, depending on discount rates, informal cooperation may be a Nash equilibrium as a result of, say, a trigger strategy being each player's best response to the other player's use of such a strategy (where a trigger strategy is one whereby a player cooperates until the other fails to cooperate, which triggers a switch to noncooperation forever after). ${ }^{26}$ However, if the system is such as to display periodic or chaotic dynamical behaviour, there is simply no reason to suppose that there would or should exist simple and compelling Nash equilibria for tax setting. Instead, active tax competition is likely to further complicate the dynamical behaviour. ${ }^{27}$ Similarly, with 'low' trade freeness and 'rapid' entrepreneurial responses to real income differences, continuing competition between the governments could result in erratic shifts from one region to the other.

We offer two final observations regarding taxation. First, it may be infeasible for governments to tax workers and to use the proceeds to subsidize entrepreneurs. In particular, taxing workers might be politically unpopular if they do not appreciate that the benefit from the cost-of-living reduction would outweigh the loss from paying tax. If subsidies are infeasible for whatever reason, we could envisage in the case of high trade freeness an equilibrium where there is agglomeration in, say, region 2 with $\tau_{1}=0$ and $\tau_{2}=1-\Omega(0)>0$, with government 1 being unable to offer the subsidy needed to attract entrepreneurs away from region 2. Thus the taxation of agglomeration rents may be

\footnotetext{
${ }^{26}$ See, for example, Gibbons (1992, Ch. 2.3.B).

${ }^{27}$ The dynamical model could be modified to suppose that governments change tax rates following relatively simple rules of thumb. Such a modification is beyond the scope of the present paper.
} 
sustainable. Second, in general, formal collusion by the governments could be beneficial for workers in both regions. The relevant constraint on collective action by governments interested in the welfare of their workers might be that, with too high taxation of profits, entrepreneurs might not be prepared to continue being entrepreneurs. It is beyond the scope of the current paper to pursue this issue. ${ }^{28}$

\section{Some Concluding Comments}

The $F E$ model is not robust with respect to its temporal specification: reformulating the model in discrete time has dramatic implications. In the continuous-time $F E$ model, longrun behaviour necessarily involves a stationary equilibrium. In contrast, the discrete-time version can also exhibit cycles of any periodicity or behave chaotically. Moreover, changing the temporal framework leads to an entirely different perception of the impact of transport costs. ${ }^{29}$ Whereas core-periphery theorists, analysing the stability of regional diversification, portray high transport costs as stabilizing, increases in transport costs emerge as de-stabilizing in a discrete-time framework. Furthermore, reformulating the $F E$ model in discrete time also recognises the importance of the speed with which entrepreneurs respond to regional differences in post-tax real incomes. In sum, we suggest, the discrete-time $F E$ model is much richer in terms of its potential for explaining and understanding economic phenomena relating to factor movements between regions and countries.

\footnotetext{
${ }^{28}$ The simplest assumption would be that the reservation post-tax income of an entrepreneur would be what that entrepreneur could get as a worker. Given that the utility of an entrepreneur is at least as high as the utility of a worker, the governments' objective could be interpreted as Rawlsian.

${ }^{29}$ See Currie and Kubin (2006).
} 
By systematically examining the implications of the new economic geography models for public policies, BFMOR have made a major contribution. Our analysis reinforces their assertion that propositions based on the basic smooth neoclassical tax competition model may be invalid in a lumpy $F E$ model. Whereas their claim relates to cases of 'high' trade-freeness, our analysis confirms that, even with 'intermediate' and 'low' trade freeness, any presumption that a small tax or subsidy change is likely to have a small and predictable long-run impact may well be invalidated.

It should be noted that Sections 5 and 6 provide insights that do not depend on the temporal framework as such, but derive rather from replacing BFMOR's assumption that tax revenues are spent on a public good that "favours labourers over owners of capital goods" by the assumption that tax proceeds are redistributed to workers. Our model constitutes, we believe, a more appealing and transparent framework for analysing government intervention designed to benefit workers through the taxation of profits. The model also accommodates the possibility that it may benefit workers for a government to subsidize profits and to finance this through taxes on workers. 


\section{Bibliography}

Alligood KT, Sauer TD, Yorke JA, 1996. Chaos: An Introduction to Dynamical Systems (Springer-Verlag, New York).

Baldwin RE, Forslid R, Martin P, Ottaviano GIP, Robert-Nicoud F, 2003. Economic Geography and Public Policy. (Princeton University Press: Princeton).

Baldwin RE, Krugman PR, 2004. Agglomeration, integration and tax harmonisation. European Economic Review 48, 1-23.

Currie M, Kubin I, 2006. Chaos in the core-periphery model. Journal of Economic Behaviour and Organization 30, forthcoming.

Devaney RL, 1989. An Introduction to Chaotic Dynamical Systems, $2^{\text {nd }}$ ed. (AddisonWesley, California).

Forslid R, 1999. Agglomeration with human and physical capital: an analytically solvable case. Discussion Paper No. 2102, Centre for Economic Policy Research.

Forslid R, Ottaviano GIP, 2003. An analytically solvable core-periphery model. Journal of Economic Geography 3, 229 - 240.

Fujita M, Krugman PR, Venables A, 1999. The Spatial Economy: Cities, regions and International Trade. (MIT Press, Cambridge).

Gibbons R, 1992. A Primer in Game Theory. (Harvester-Wheatsheaf, Herfordshire).

Krugman PR, 1991. Increasing returns and economic geography. Journal of Political Economy 99, 483-499.

Ottaviano GIP, 2001. Monopolistic competition, trade, and endogenous spatial fluctuations. Regional Science and Urban Economics 31, 55-77. 
Puga D, 1998. Urbanization patterns: European versus less developed countries. Journal of Regional Science 38, 231-52. 